\title{
A defined metabolic state in pre B cells governs B-cell development and is counterbalanced by Swiprosin-2/ EFhd1
}

\author{
Merle Stein ${ }^{1,6,7}$, Sebastian Dütting ${ }^{1,6}$, Dimitrios Mougiakakos ${ }^{2}$, Michael Bösl ${ }^{3}$, Kristin Fritsch ${ }^{1}$, Dorothea Reimer ${ }^{1}$, Sophia Urbanczyk ${ }^{1}$, \\ Tobit Steinmetz ${ }^{1}$, Wolfgang Schuh ${ }^{1}$, Aline Bozec ${ }^{4}$, Thomas H Winkler ${ }^{5}$, Hans-Martin Jäck ${ }^{1}$ and Dirk Mielenz ${ }^{\star, 1}$
}

B-cell development in the bone marrow comprises proliferative and resting phases in different niches. We asked whether B-cell metabolism relates to these changes. Compared to pro B and small pre B cells, large pre B cells revealed the highest glucose uptake and ROS but not mitochondrial mass, whereas small pre B cells exhibited the lowest mitochondrial membrane potential. Small pre B cells from Rag $1^{-l-} ; 33 . C 9 \mu$ heavy chain knock-in mice revealed decreased glycolysis (ECAR) and mitochondrial spare capacity compared to pro $B$ cells from Rag $1^{-I-}$ mice. We were interested in the step regulating this metabolic switch from pro to pre $B$ cells and uncovered that Swiprosin-2/EFhd1, a Ca ${ }^{2+}$-binding protein of the inner mitochondrial membrane involved in $\mathrm{Ca}^{2}$ ${ }^{+}$-induced mitoflashes, is expressed in pro B cells, but downregulated by surface pre B-cell receptor expression. Knockdown and knockout of EFhd1 in 38B9 pro B cells decreased the oxidative phosphorylation/glycolysis (OCR/ECAR) ratio by increasing glycolysis, glycolytic capacity and reserve. Prolonged expression of EFhd1 in EFhd1 transgenic mice beyond the pro B cell stage increased expression of the mitochondrial co-activator PGC-1 $\alpha$ in primary pre B cells, but reduced mitochondrial ATP production at the pro to pre B cell transition in IL-7 cultures. Transgenic EFhd1 expression caused a B-cell intrinsic developmental disadvantage for pro and pre B cells. Hence, coordinated expression of EFhd1 in pro B cells and by the pre BCR regulates metabolic changes and pro/pre B-cell development.

Cell Death and Differentiation (2017) 24, 1239-1252; doi:10.1038/cdd.2017.52; published online 19 May 2017

The hallmark of $\mathrm{B}$-cell development is a continuous selection pressure imposed on pre B and B-cell receptors (BCRs), consisting of immunoglobulin (Ig) light chains (LCs) and heavy chains (HCs). ${ }^{1,2} \mathrm{Ig} \mu \mathrm{HC}$ genes are rearranged in pro B cells and LC genes in small pre B cells. ${ }^{3,4}$ Mice deficient in Rag genes show a developmental block at the pro B-cell stage and accumulate pro B cells in the BM. ${ }^{4} \mathrm{~A}$ rearranged $\mu \mathrm{HC}$ together with the surrogate $L C$, VpreB and $\lambda 5$, forms the pre BCR in pre B cells. Hence, expression of a $\mu \mathrm{HC}$ on a Rag2 ${ }^{-1-}$ background in mice rescues development of phenotypic pre B cells. ${ }^{3}$ Expression of the pre BCR inhibits further rearrangements of $\mathrm{V}$ to $\mathrm{D}-\mathrm{J}$ loci of the not yet rearranged $\mu \mathrm{HC}$ (allelic exclusion). ${ }^{1}$ The pre BCR also elicits an increase in the cytosolic $\mathrm{Ca}^{2+}$ concentration ${ }^{5}$ and acts as an inducible proliferative signal of pre $B$ cells with an expansion factor of 20-100 (about four to six cell divisions). ${ }^{6}$ IL-7 provides important signals for pro B-cell proliferation ${ }^{7}$ via stabilization of mitochondria. ${ }^{8}$ In vitro, IL-7 supports the proliferation of pro B cells expressing ckit (Hardy fraction B and C). ${ }^{9,10}$ IL-7 also promotes glycolysis via Akt activation, $8,11,12$ but from pro to immature B cells, the responsiveness to IL-7 decreases. ${ }^{7,13}$ In parallel to the decreasing IL-7 responsiveness, the pre BCR initiates expression of SLP-65/BLNK. This allows large pre B differentiation into small pre $B$ cells through inhibition of the PI3K/Akt pathway and upregulation of FOXO1. ${ }^{13-15}$ LC rearrangement in small pre $B$ cells enables $B C R$ expression on immature $B$ cells that migrate to the spleen and mature to resting follicular and marginal zone $B$ cells. Resting splenic $B$ cells exhibit a low metabolic activity and consume fatty acids to produce ATP via oxidative phosphorylation (OxPhos). ${ }^{16}$ Upon activation through the BCR or through TLR4 by lipopolysaccharide, murine $\mathrm{B}$ cells upregulate both OxPhos and glycolysis, concomitant with the glucose transporter glut1, in a balanced ratio. ${ }^{16}$ Anabolic pathways, controlled by PI3K/Akt/ mTor or Erk, favor proliferation and often rely on glycolysis. ${ }^{17}$ In particular, the PI3K and Erk pathways control proliferation during pre B cell development. ${ }^{12,13,18}$ Genes controlling mitochondria and glycolysis are targets of the pre BCR and the BCR. ${ }^{16,19}$ This infers that the metabolic machinery of $B$ cells integrates signals downstream of (pre) BCR receptors together with growth factors, ${ }^{13,16}$ The pre B cell checkpoint is subject to control by cellular metabolism: mice with a null

\footnotetext{
${ }^{1}$ Department of Internal Medicine 3, Division of Molecular Immunology, Nikolaus-Fiebiger-Center, Friedrich-Alexander-University of Erlangen-Nuremberg, Erlangen, Germany; ${ }^{2}$ Department of Internal Medicine V, University Clinic, Friedrich-Alexander-University of Erlangen-Nuremberg, Erlangen, Germany; ${ }^{3}$ Department of Experimental Biomedicine, University Hospital and Rudolf Virchow Center, University of Würzburg, Würzburg D-97080, Germany; ${ }^{4}$ Department of Internal Medicine III, University Clinic, Friedrich-Alexander-University of Erlangen-Nuremberg, Erlangen, Germany and ${ }^{5}$ Department of Biology, Nikolaus-Fiebiger-Center, Friedrich-Alexander-University of Erlangen-Nuremberg, Erlangen, Germany

${ }^{*}$ Corresponding author: Dirk Mielenz, Department of Internal Medicine 3, Division of Molecular Immunology, Nikolaus-Fiebiger-Center, Friedrich-Alexander-University of Erlangen-Nuremberg, Glueck street 6a, Erlangen 91054, Germany. Tel: +49 9131853 9105; Fax: +49 9131853 9343; E-mail: dirk.mielenz@fau.de

${ }^{6}$ These authors contributed equally to this work.

${ }^{7}$ Current address: Institute of Comparative Molecular Endocrinology (CME), University of Ulm, Ulm 89081, Germany.

Received 04.8.16; revised 10.2.17; accepted 08.3.17; Edited by L Scorrano; published online 19.5.17
} 
mutation of the folliculin-interacting protein 1 (Fnip1) reveal a block at the large pre B-cell stage due to imbalanced metabolism. ${ }^{20}$ However, these data cannot explain the pro/ pre B-cell transition. Swiprosin-2/EFhd1 (EFhd1) ${ }^{21}$ is a protein of the inner mitochondrial membrane..$^{22-24}$ We revealed its expression only in the Bcr-Abl expressing pro B-cell line $38 \mathrm{~B} 9,{ }^{25}$ but not in $\mathrm{B}$-cell lines expressing a pre $\mathrm{BCR}$ or a $\mathrm{BCR}^{26}$ EFhd1 is a target gene of two transcription factors

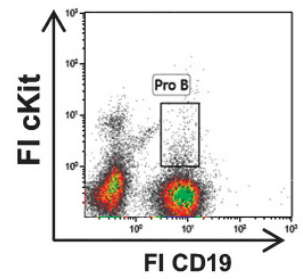

b

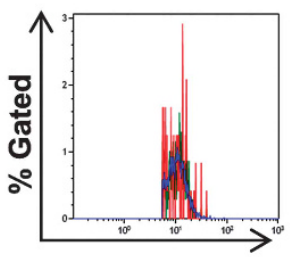

Mitotracker Green (mitochondrial mass)

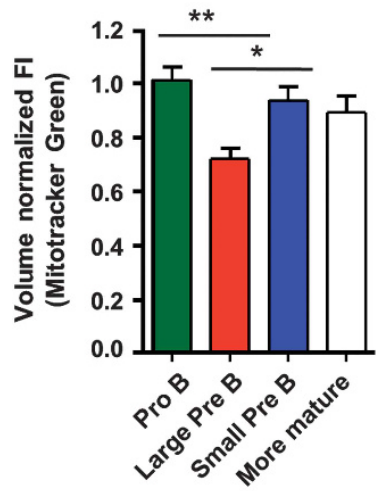

f

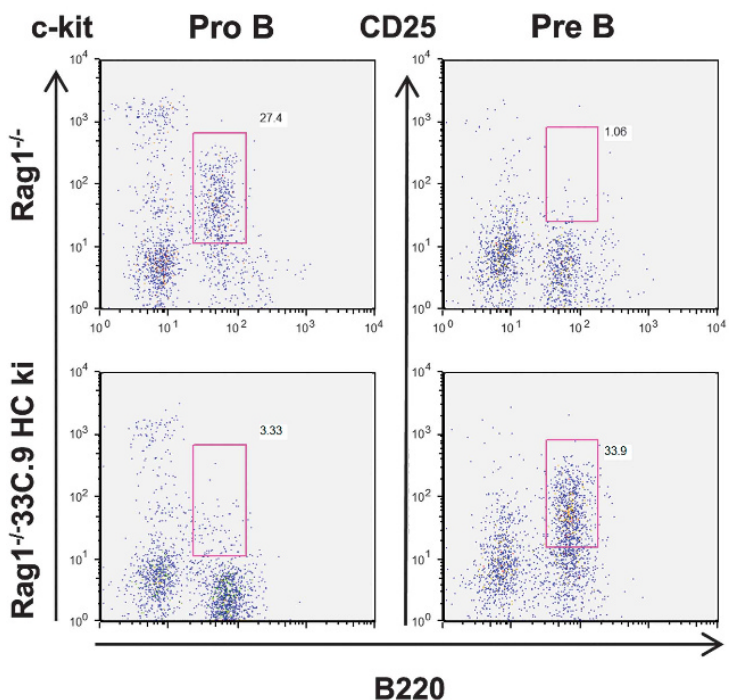

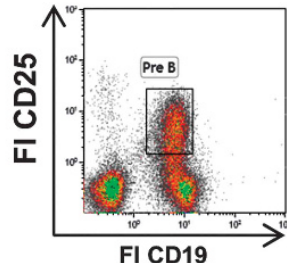

c

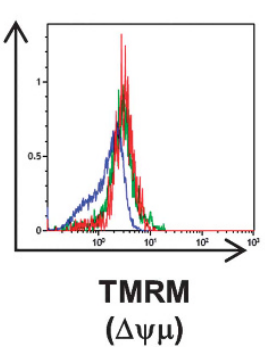

d

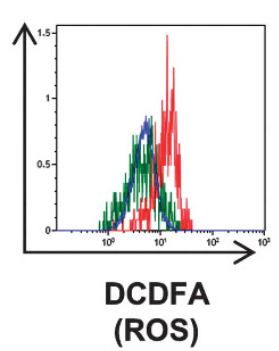

e

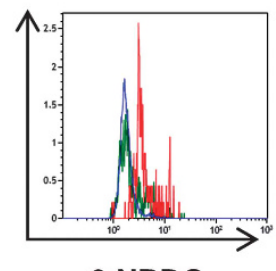

6-NBDG

(Glucose uptake)
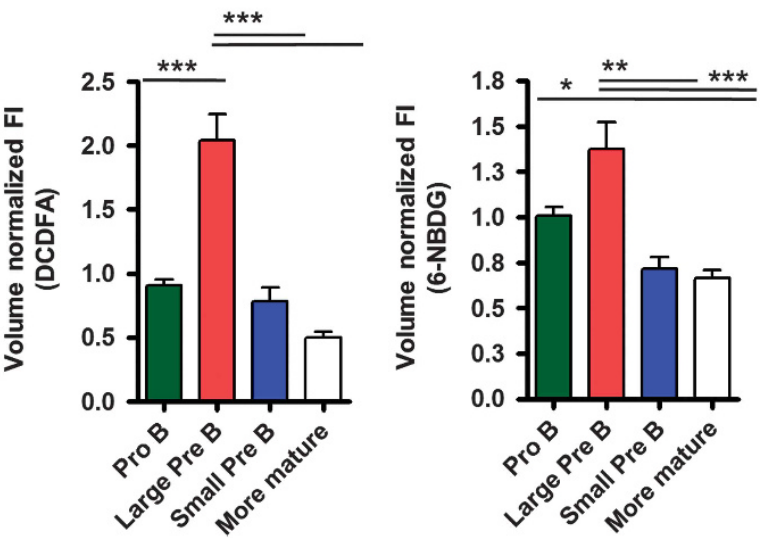

g

$\square \operatorname{Rag}^{1 /}$

Rag1/-33.C9 HC ki

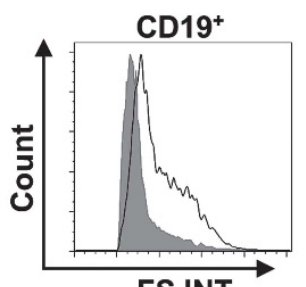

h

$\square \operatorname{Rag} 1^{-/}$

Rag1 ${ }^{-/-33 . C 9 ~ H C ~ k i ~}$

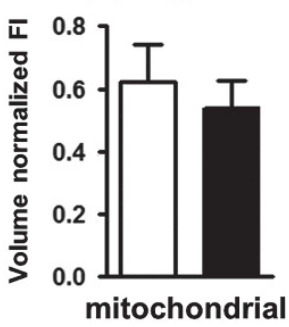

mass
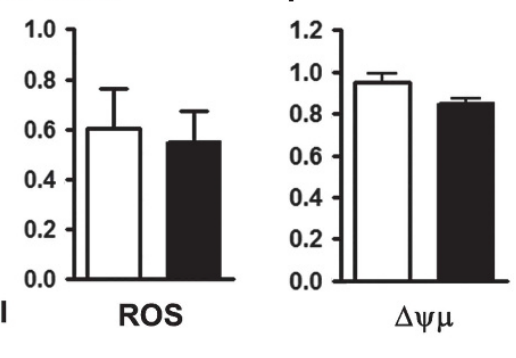
involved in B-cell identity and control of early B-cell development, Foxo1 and Brg1, in pro B cells. ${ }^{27,28}$ In very aggressive human melanomas, EFhd1 is co-expressed with PGC-1a, a co-activator of PPAR that is involved in mitochondrial biogenesis. $^{29}$ EFhd1 becomes upregulated, together with PGC-1a, UCP2 and other proteins involved in mitochondrial function, in distal convoluted tubule cells of the kidney through deletion of the cytosolic $\mathrm{Ca}^{2+}$ buffer parvalbumin ${ }^{30}$ and is a positive regulator of mitochondrial flashes (mitoflashes) via $\mathrm{Ca}^{2+}$ binding to its EF hands. ${ }^{31}$ Mitoflashes indicate stochastic and brief periods of alkalinization in individual mitochondria, possibly as a result of acceleration in proton pumping, triggered by mitochondrial fusion and/or a change in ion homeostasis. ${ }^{32}$ Here, we tested the hypothesis that metabolism is altered during early B-cell development in the BM. We reveal that EFhd1 is normally downregulated by the pre BCR. Prolonged expression of EFhd1 beyond the pro B-cell stage in transgenic mice (EFhd1tg) counterbalances metabolic changes induced through the pre BCR. Hence, regulation of mitochondrial genes and metabolism by the pre BCR is crucial for B-cell development.

\section{Results}

Metabolism changes at the pro $B$ to small pre $B$ transition. To characterize metabolic changes during early B-cell development in the BM, we used flow cytometry and assessed total mitochondrial mass (Mitotracker Green), mitochondrial membrane potential $(\Delta \psi \mu$; TMRM), reactive oxygen species (ROS) (DCDFA) and glucose uptake (6NBDG) normalized to cell size ${ }^{33}$ (Figures 1a-e). Assessment of $\Delta \psi \mu$ with TMRM was calibrated with a protonophore (Supplementary Figure S1). Mitochondrial mass relative to cell size went down in large pre B cells, but remained constant during later B-cell development (Figure 1b). Pro B cells exhibited the highest $\Delta \psi \mu$ that decreased significantly in small pre B cells (Figure 1c). ROS production (Figure 1d) and glucose uptake (Figure 1e) were highest in large pre B cells and were reduced again in small pre $B$ cells. We concluded that large pre $B$ cells are metabolically more active than small pre $B$ cells without having increased mitochondrial mass. These data correlate well with clonal expansion of large pre B cells. To functionally test for a metabolic transition of pro to small pre $\mathrm{B}$ cells, we established a $\mu \mathrm{HC}$ knock-in (ki) mouse model (33.C9 $\mu \mathrm{HCki})$ and crossed these mice to Rag1 ${ }^{-/-}$ mice $^{4}$ (Rag1 $^{-1-} ; 33 . \mathrm{C} 9 \mu \mathrm{HCki}$ ). In accordance with other transgenic $\mu \mathrm{HC}$ crossed onto a Rag-deficient background, ${ }^{3}$ 33. $\mathrm{C} 9 \mu \mathrm{HC}$ expression established pre B-cell development (Figure 1f). Pre B cells from Rag1 ${ }^{-/-} ; 33 . \mathrm{C} 9 \mu \mathrm{HCki}$ mice were mainly small (Figure $1 \mathrm{~g}$ ). In full accordance with data from wild-type (WT) pro and small pre B cells, Rag1 $1^{-/-} ; 33$. C9 $\mu \mathrm{HCki}$ pre B cells showed no difference in mitochondrial mass and ROS when compared to $R a g 1^{-1-}$ pro B cells (Figure $1 \mathrm{~h})$, and a trend towards reduced $\Delta \psi \mu(P=0.055)$ as shown by flow cytometry and confocal microscopy (Figure 1h; Supplementary Figure S1). We then used a functional assay to assess metabolic activity of pro and small pre B cells. Extracellular flux analyses performed with a Seahorse device revealed in general a reduced oxygen consumption rate (OCR; an indicator for oxidative phosphorylation/OxPhos) and extracellular acidification rate (ECAR; an indicator for aerobic glycolysis) in Rag1 $1^{-/-} ; 33 . C 9 \mu \mathrm{HCki}$ pre B cells (Figures $2 \mathrm{a}-\mathrm{c}$ ). However, in relation, glycolysis was reduced significantly more; therefore, the OCR/ECAR ratio tended to increase (Figures $2 b$ and $c$ ). In accordance, there were trends towards better mitochondrial coupling efficiency and less proton leak (Figure 2c). In contrast, mitochondrial spare capacity (maximal/basal $\mathrm{O}_{2}$ consumption) was significantly reduced in Rag $1^{-1-} ; 33 . \mathrm{C} 9 \mu \mathrm{HCki}$ pre $\mathrm{B}$ cells, and there were tendencies towards less mitochondrial ATP production and respiration (Figure $2 \mathrm{c}$ ). We conclude that expression of the pre BCR ultimately promotes metabolic quiescence, with a dominant reduction of glycolysis. A remaining question was how the metabolic transition of pro over highly active pre $B$ cells towards rather inactive small pre B cells is handled.

The pre BCR downregulates EFhd1. To assess the relevance of the metabolic switch at the pro/pre B-cell transition, we made use of the EF hand containing $\mathrm{Ca}^{2}$ +-binding mitochondrial protein Swiprosin-2/EFhd1. We had detected its expression only in the pro B-cell line 38B9. ${ }^{26} \mathrm{RT}$ $\mathrm{PCR}$ analysis of sorted $\mathrm{BM} B$ cells $^{34}$ revealed the strongest efhd1 mRNA expression in pro B cells (Figure 3a). Western blot analysis of pro $B$ cells from Rag $1^{-/}$mice confirmed EFhd1 protein expression in pro B cells. EFhd1 was neither detectable in total $\mathrm{BM} \mathrm{IgM}^{+} \mathrm{CD}^{+} 9^{+} \mathrm{B}$ cells because pro $\mathrm{B}$ cells represent only $1 \%$ within $\mathrm{CD}^{+} 9^{+}$cells, nor in $\mathrm{CD} 19^{-}$ cells (Figure $3 b$ ). Retroviral transduction of the Rag2 ${ }^{-/-} \mathrm{IL}-7$ dependent pro $\mathrm{B}$ cell line $\mathrm{R}_{5 \mathrm{~B}}{ }^{35}$ with recombined $\mu \mathrm{HC}$ (functional $\mu \mathrm{HC}, \mu \mathrm{fct}$ ) showed that surface pre BCR formation led to downregulation of EFhd1 at the protein level (Figure 3c). Cytoplasmic $\mu \mathrm{HC}$ expression, which was achieved by expression of the dysfunctional $\mu \mathrm{HC} \mathrm{VH} 81 . \mathrm{X}$

Figure 1 Analysis of mitochondrial activity and glucose uptake of pro and pre B cells by flow cytometry. (a) BM cells from C57BL/6 mice were incubated with fluorescent

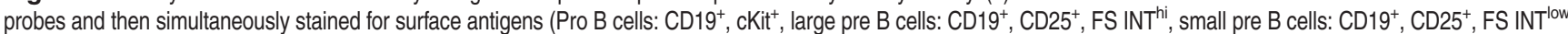
and more differentiated B-cell populations $\left(\mathrm{CD} 19^{+}, \mathrm{CKit}^{-}, \mathrm{CD} 25^{-}\right)$and analyzed by flow cytometry. Representative plots of the median fluorescence intensity for Mitotracker Green (b), TMRM (c), DCFDA (d) and 6-NBDG (e) are shown. Fluorescence was normalized to spheroid cell volume by FS TOF signal as an indicator for cell size. TMRM fluorescence was normalized with CCCP. Data were normalized to pro B cells and are represented as median \pm S.E.M., $n=10$ C57BL/6 mice from two experiments (b, $\mathbf{d}$ and $\mathbf{e}), n=5$ mice from four experiments (c). Significance was tested by ANOVA with Bonferroni correction, except for $C$ (two-tailed Student's $t$-test; only pro and small pre B cells were compared). (f) BM of Rag1 $1^{-1-}$ and Rag1 ${ }^{-1-} 33 . C 9 \mu \mathrm{HCki}$ mice was analyzed by flow cytometry (Pro B cells: CD19 ${ }^{+}$, cKit ${ }^{+}$, pre B cells: CD19 ${ }^{+}, \mathrm{CD} 25^{+}$), (g) Histograms representing FS Int of

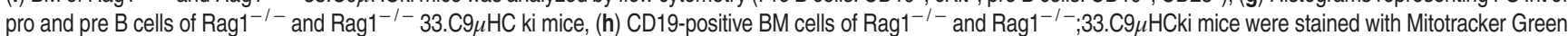
and DCDFA, analyzed by flow cytometry and normalized to cell volume and pro B cells. Results are represented as mean \pm S.D., $n=5$, (i) CD19-positive BM cells of 5 Rag1 ${ }^{-1-}$ and Rag1 ${ }^{-l-} ; 33$.C9 $\mu \mathrm{HCki}$ mice were stained with TMRM, duplicate CCCP-calibrated samples were analyzed by flow cytometry and normalized to cell volume and pro B cells. Results are represented as mean \pm S.E. 

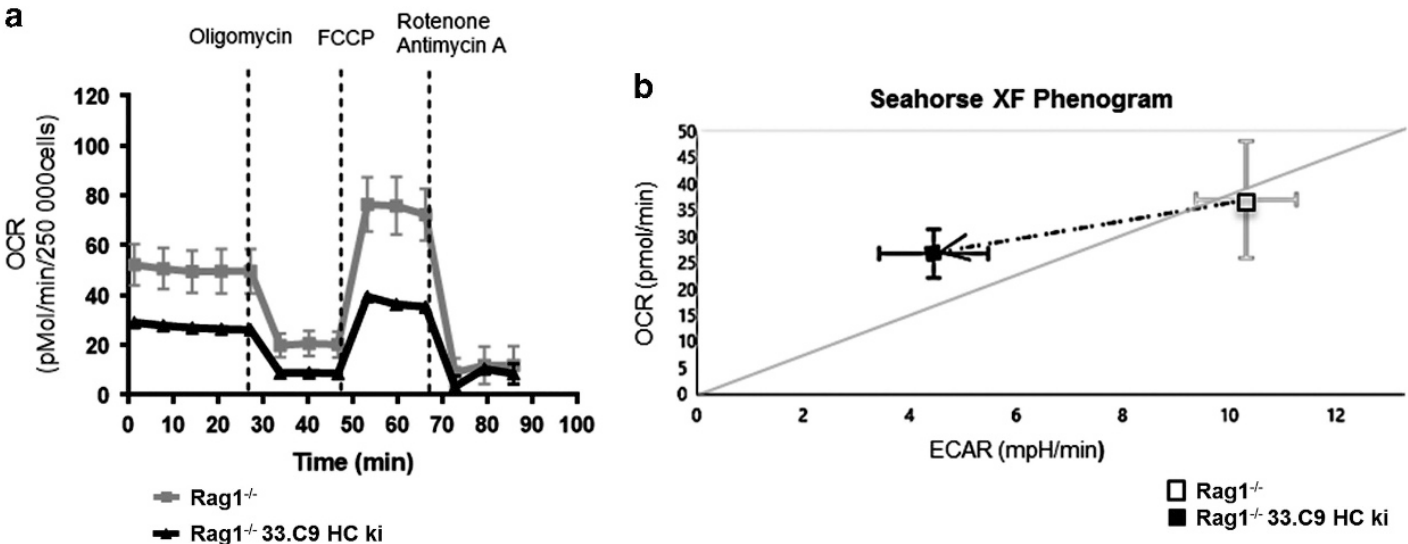

C
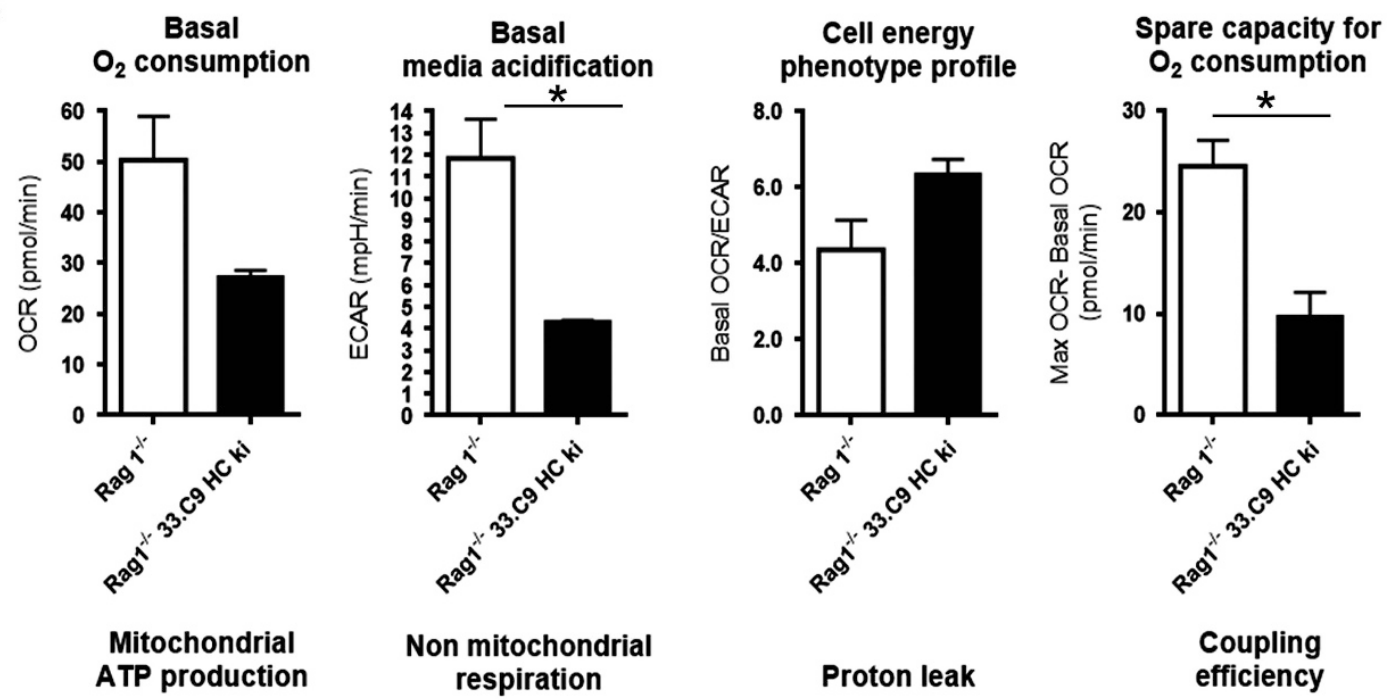

Proton leak
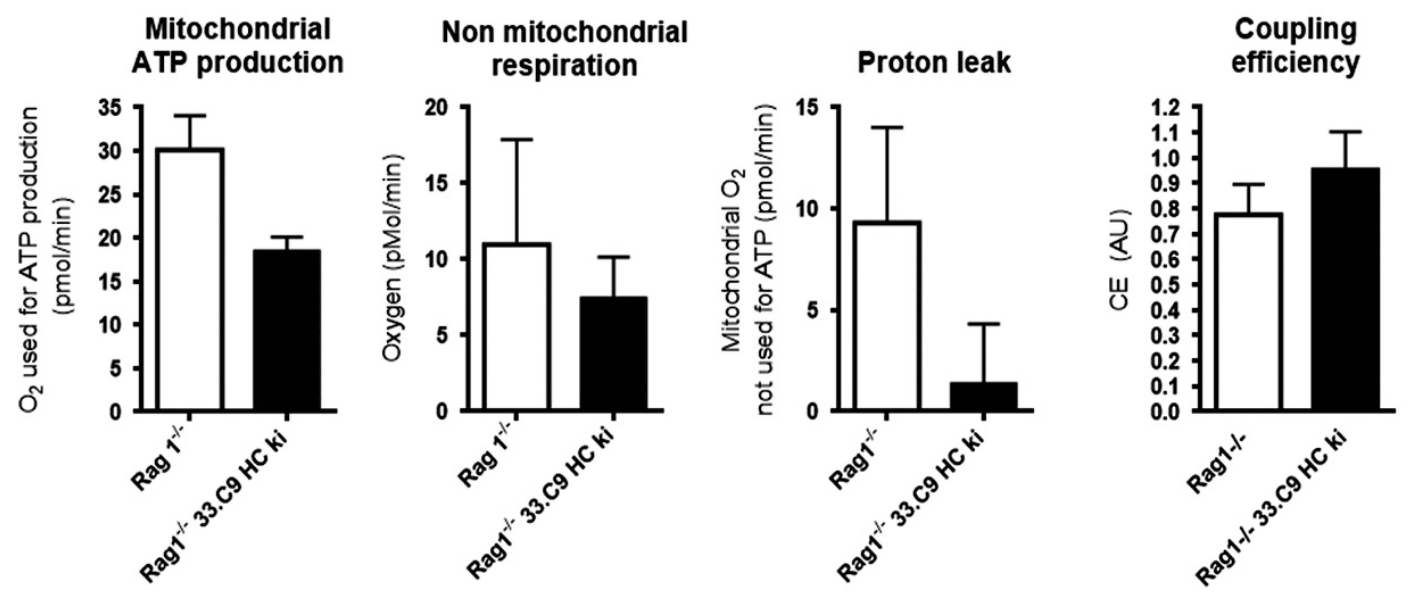

Figure 2 Influence of $\mu$ heavy chain expression on metabolic activity of BM B lymphocytes. (a) BM cells of Rag $1^{-1-}$ and Rag $1^{-1-} ; 33$.C9 $\mu \mathrm{HCki} \mathrm{mice} \mathrm{were} \mathrm{pooled} \mathrm{and} \mathrm{pro}$

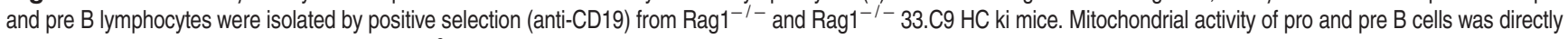
analyzed by Mito Stress Test with a Seahorse $\mathrm{XF}^{\mathrm{e}} 96$ extracellular flux analyzer. Five readings were taken for basal oxygen consumption rate (OCR) before subsequent addition of oligomycin, FCCP and antimycin+rotenone; summary of three experiments with each two to four pooled mice, (b) Representative cellular energy phenotype profiles (basal OCR/ basal extracellular acidification (ECAR) of Rag $1^{-1-}$ and Rag1 $1^{-1-} ; 33 . C 9 \mu \mathrm{HCki}$ cells from one experiment are compared in a 2D plot, (c) The basal OCR, ECAR and the cell energy phenotype profile (OCR/ECAR) are shown as bar diagrams. Also shown are the mitochondrial spare capacity (the increase from basal to maximum OCR when uncoupling mitochondrial proton flow by FCCP), the mitochondrial ATP production rate (OCR, which can be blocked by adding the mitochondrial ATPase inhibitor oligomycin), the non-mitochondrial respiration $\left(\mathrm{O}_{2}\right.$ consumption after inhibition of mitochondria by oligomycin, (FCCP), antimycin and rotenone), proton leak (difference in $\mathrm{O}_{2}$ consumption after oligomycin and full mitochondrial inhibition by additional antimycin A and rotenone) and coupling efficiency (ratio of mitochondrial ATP production and proton leak). Summary of $n=3$ with each two to four pooled mice 


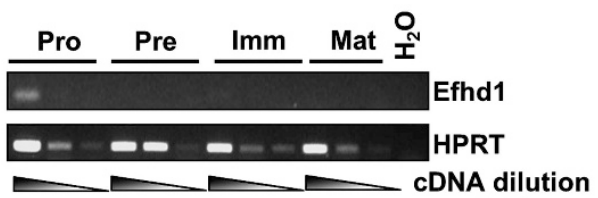

(1:5)

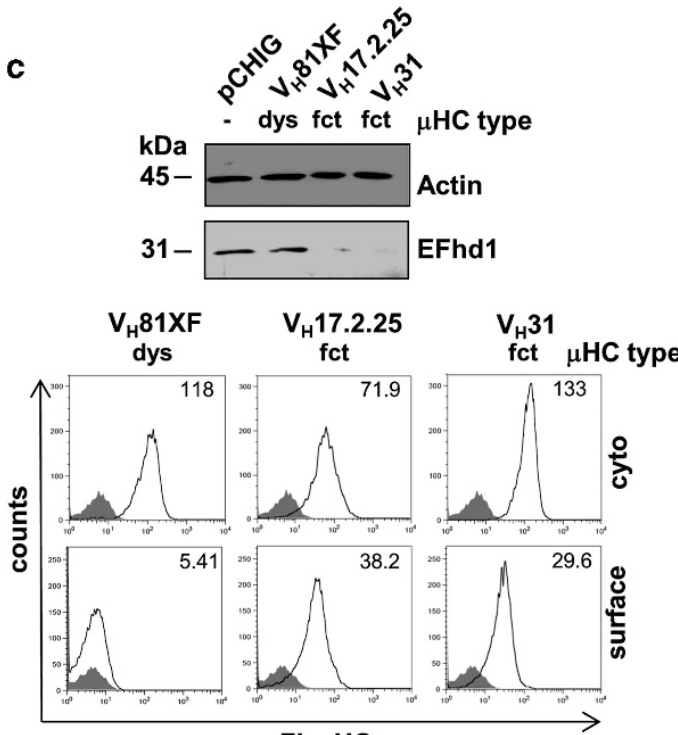

$\mathrm{FI} \mu \mathrm{HC}$

f

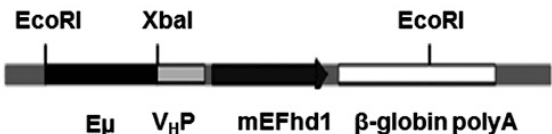

g

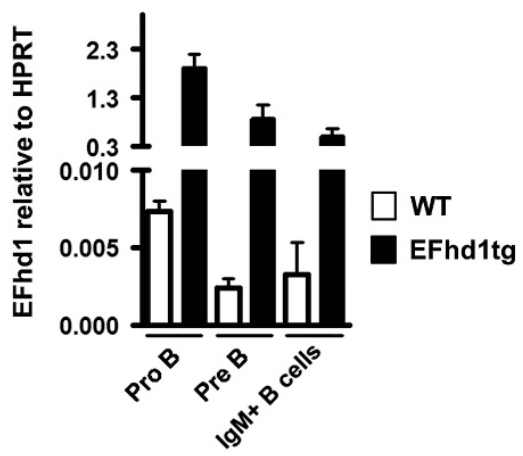

b

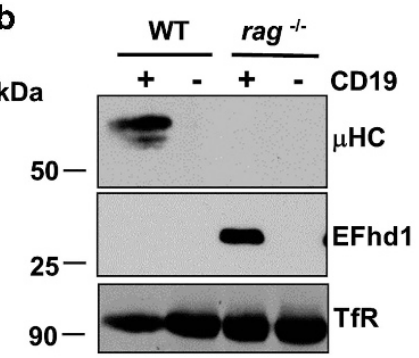

d

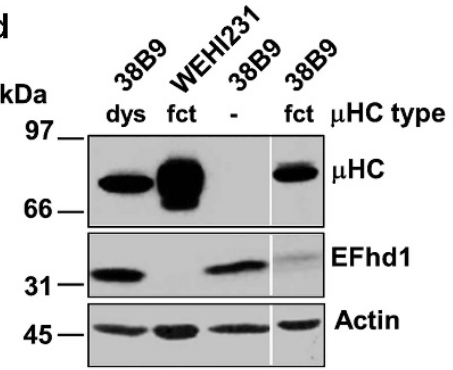

e

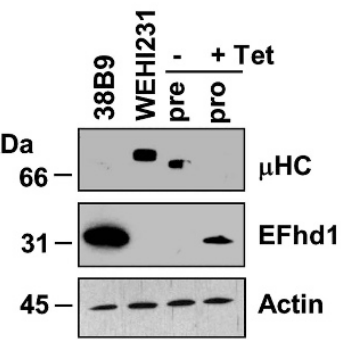

h

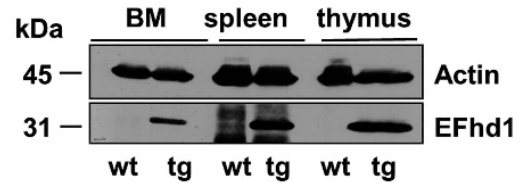

Figure 3 Downregulation of EFhd1 by the pre BCR and establishment of EFhd1tg mice. (a) Pro, pre and immature B cells of the BM were isolated through FACS and mature $\mathrm{B}$ cells of the spleen by MACS. Total RNA from the indicated cells was isolated, reversely transcribed to CDNA and amplified with efhd1 or hprt-specific primers in fivefold serial dilutions, (b) BM cells of WT and Rag1 ${ }^{-1-}$ mice positively purified via anti-CD19 and protein lysates of CD19 ${ }^{+}$and CD19- cells were subjected to western blot analysis using anti transferrin receptor (TfR), anti $\mu \mathrm{HC}$ and anti EFhd1 antibodies, (c) IL-7-dependent $\mu \mathrm{HC}$-negative R5B pro B cells were infected with retroviral particles derived from pCHIG or various functional (fct) and dysfunctional (dys) $\mu \mathrm{HC}$ idiotypes cloned into $\mathrm{pCHIG}$, selected and analyzed by western blot using anti Actin and anti EFhd1 antibodies (upper panel). Cells were either analyzed for surface $\mu \mathrm{HC}$ or cytoplasmic $\mu \mathrm{HC}$ expression by flow cytometry (lower panel). MFI is indicated, (d) Lysates of WEHI231 cells, $38 \mathrm{~B} 9$ cells expressing no $\mu \mathrm{HC}$, a dysfunctional or a functional $\mu \mathrm{HC}$ were subjected to western blot analysis using anti $\mu \mathrm{HC}$, anti Actin and anti EFhd1 antibodies. Alle lanes are from the same western blot and exposure, (e) Lysates of 38B9, WEHI231 and pro and pre B cells obtained from a double transgenic tetracycline (tet)-off controlled SP6 $\mu \mathrm{HC}$ expression system were subjected to western blot analysis using anti $\mu \mathrm{HC}$, anti Actin and anti EFhd1 antibodies. In this experiment, $73.6 \%$ of induced cells (- tet) expressed the SP6 $\mu \mathrm{HC}$, (f) Schematic of the transgenic expression cassette, $\mathrm{E} \mu: \mu$ enhancer, $\mathrm{V}_{\mathrm{H}} \mathrm{P}: \mathrm{V}_{\mathrm{H}}$ promoter, $(\mathrm{g})$ Pro, pre and immature $\mathrm{B}$ cells isolated through FACS from wild-type or EFhd1tg mice were analyzed by qPCR for EFhd1 expression, (h) Protein lysates of total BM, spleen and thymus were analyzed by western blot using anti Actin and anti EFhd1 antibodies. Molecular mass standards are indicated on the left $(\mathrm{kDa})$ 
a
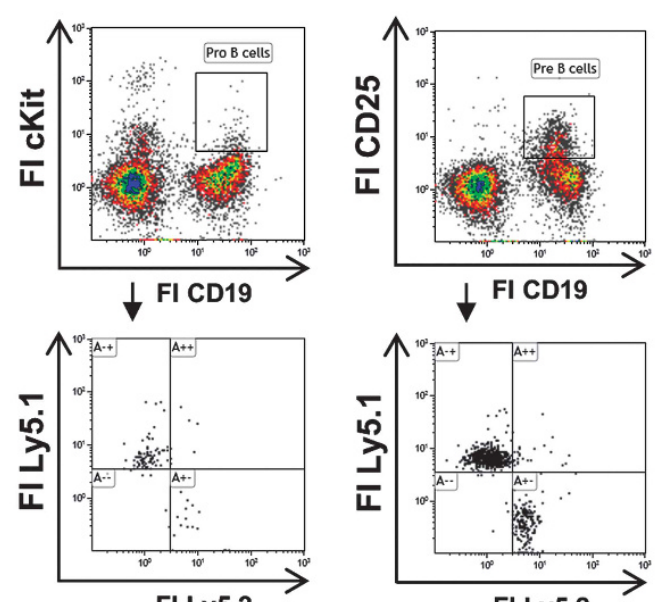

FI Ly5.2

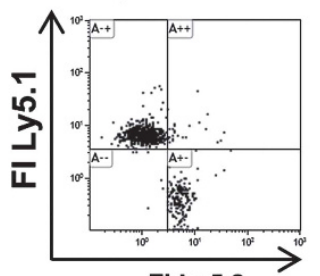

FI Ly5.2

b

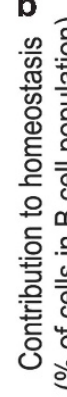

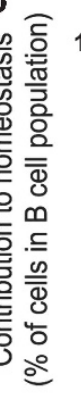

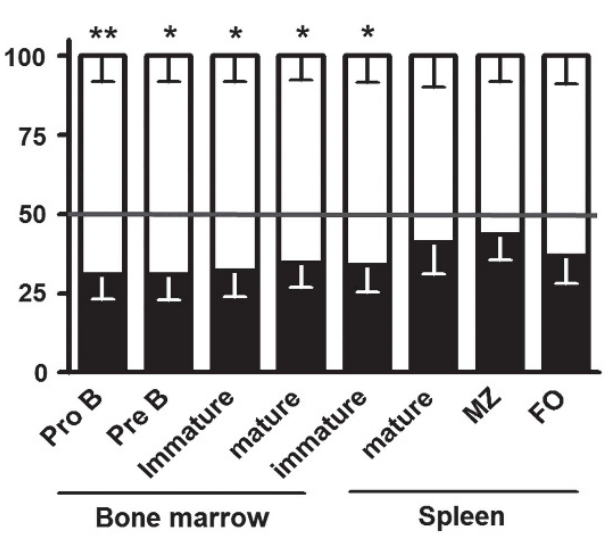

Ly5.2 (EFhd1tg)

Ly5.1 (WT)

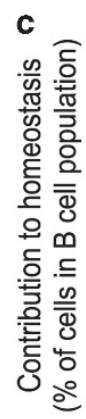

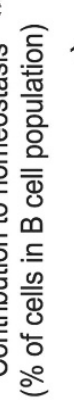

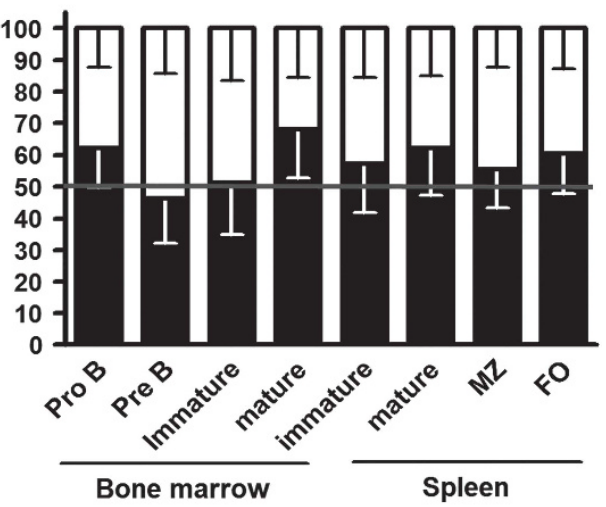

Ly5.2 (WT)

Ly5.1 (WT)

( $\mu$ dys), ${ }^{36}$ could not downregulate EFhd1 (Figure 3c). Similar results were obtained with 38B9 cells (Figure $3 d$ ). Inducible expression of the pre BCR by removal of tetracycline of pro B-cell cultures from Rag2 ${ }^{-/-}$dTg (Ig-tTA/tet- $\mu$ ) mice ${ }^{6}$ led to downregulation of EFhd1 on the protein level in those primary cells (Figure $3 e$ ). Retrospective analysis of microarray data of
Figure 4 Contribution of EFhd1tg precursors to B-cell development in mixed bone marrow chimeras. CD45.1 BL6 (Ly5.1) recipient mice were lethally irradiated with 11 Gy and reconstituted with $1 \times 10^{6}$ WT CD45.1 (Ly5.1) and $1 \times 10^{6}$ CD45.2 (Ly5.2) EFhd1tg or wild-type liitermate BM cells. After 6 weeks repopulation, the contribution of CD45.1 and CD45.2 to B-cell populations in the BM and spleen was analyzed by flow cytometry for pro $\mathrm{B}\left(\mathrm{CD} 19^{+}, \mathrm{cKit}^{+}\right)$, pre $\mathrm{B}\left(\mathrm{CD} 19^{+}, \mathrm{CD} 25^{+}\right)$, immature $\left(\mathrm{CD} 19^{+}, \operatorname{lgM}^{+}, \lg \mathrm{D}^{-}\right)$, mature $\left(\mathrm{CD} 19^{+}, \operatorname{lgM}{ }^{+}, \lg \mathrm{D}^{+}\right)$, marginal zone $\left(\mathrm{CD} 19^{+}, \mathrm{CD} 21^{\text {high }}\right.$, $\mathrm{CD}^{-} 3^{-}$) and follicular $\left(\mathrm{CD} 19^{+}, \mathrm{CD} 21^{\text {low }}, \mathrm{CD} 23^{+}\right) \mathrm{B}$ cells. (a) Representative analysis of WT/EFhd1tg chimeras. (b) Summary of WT/EFhd1tg chimeras. (c) Summary of WTNT chimeras. Data are represented as mean+S.E.M. of 7-11 mice from four experiments. Statistics was done by Mann-Whitney- $U$ test

pre BCR-regulated genes ${ }^{19}$ confirmed these results (efhd1 signal in pro B cells: array $1 / 2$, raw data $625.5 / 723.9$, efhd1 signal in pre B cells: array 1/2, raw data 90.6/147.2). We reasoned that the downregulation of efhd1 by the pre BCR could support a hitherto unknown role of the pre BCR in regulating metabolic function.

Ectopic EFhd1 expression distorts early B-cell development. To test whether pre-BCR-induced downregulation of EFhd1 serves as a metabolic checkpoint, we generated EFhd1 transgenic mice (EFhd1tg) expressing EFhd1 under control of the $\mathrm{E} \mu$ enhancer and $\mathrm{V}_{\mathrm{H}}$ promoter (Figure $3 \mathrm{f}$ ). Southern blot and circle PCR analysis revealed that seven copies of the transgene had inserted in a non-coding region of the gene ms4a12 on chromosome 19 (data not shown). Ms4a12 is a colon-specific protein, ${ }^{37}$ and thus, integration of the EFhd1 transgene per se should not interfere with B cell development. Quantitative PCR (qPCR) analysis confirmed ectopic expression of EFhd1 in pre B cells and $\operatorname{lgM}^{+} B$ cells, and once more its downregulation in WT pre B cells (Figure $3 \mathrm{~g}$ ). Ectopic EFhd1 protein was detected in BM, spleen and thymus, because the $\mathrm{E} \mu$ enhancer is also active in T cells (Figure $3 \mathrm{~h}$ ). ${ }^{38}$ Interestingly, we also noted reduced expression of ectopic EFhd1 in pre B cells (Figure $3 \mathrm{~g}$ ), suggesting that only a certain expression level of EFhd 1 is tolerated in pre B cells. Hence, we tested whether prolonged EFhd1 expression intrinsically affects early B-cell development. Mixed BM chimeras (EFhd1tg; Ly5.2/WT; Ly5.1 or WT; Ly5.2/WT; Ly5.1) (Figure 4a) showed a competitive disadvantage of EFhd1 tg B cells in the pro B, pre B, immature B-cell compartments in BM and spleen, as well as in recirculating BM B cells (Figure $4 b$ ). This was not due to differential homing (Supplementary Figure S2). WT/WT chimeras did not show significant differences (Figure 4c). Thus, prolonged expression of EFhd1 beyond the pro B-cell stage and ectopic expression of EFhd1 in pro B cells distorts early B-cell development. We next sorted pro, pre (large and small) and $\operatorname{lgM}^{+} B$ cells from $\mathrm{BM}$ and assessed expression of genes involved in glucose uptake (glut1), mitochondrial function, biogenesis and ROS detoxification (ppargc1a, ppargc1b, sod2, ucp2, ucp3). ${ }^{39,40}$ Pre B cells expressed more ebf1, as expected, ${ }^{41}$ and upregulated ppargc1a (encoding PGC-1a), glut1, ucp3 and sod2 (Figure 5a). Upregulation of sod2 in pre B cells correlates well with its function in suppressing EFhd1 expression. ${ }^{42}$ Ppargc1b became strongly upregulated in $\operatorname{lgM}^{+} \mathrm{B}$ cells (Figure $5 \mathrm{a}$ ). EFhd1 expression significantly enhanced ppargc1a mRNA in 
pre B cells. Interestingly, upregulation of ppargc1a by EFhd1 was also visible in in pre B cells of IL-7 cultures (Figure $5 \mathrm{~b}$ ). Whereas $\operatorname{lgM}^{+} \mathrm{B}$ cells downregulated $u c p 2$, pre B cells, and $\operatorname{lgM}^{+} \mathrm{B}$ cells upregulated ucp3, pointing to a change in mitochondrial coupling. As EFhd1 upregulated PGC-1a but rather prevented upregulation of glut1, an Akt target gene ${ }^{43}$ in pre $B$ cells (Figure 5), we next evaluated expression of genes involved in PGC-1a and Akt pathways through qPCR arrays $\left(\mathrm{RT}^{2}\right.$ profiler) using cDNA of sorted pre $\mathrm{B}$ cells (pool of large and small) (Figures $5 c$ and d). These experiments uncovered a significant EFhd1-mediated upregulation of the PGC-1a target gene carnitine palmitoyl transferase 2 (cpt2) ${ }^{44}$ and downregulation of pten (Figure $5 \mathrm{c}$ ). Most of the other genes upregulated by EFhd1, although not significantly in this assay, are PGC-1a target genes ${ }^{44}$ (Figure $5 \mathrm{c}$ ). Our analysis also unraveled dysregulation of the Akt pathway (Figure $5 d$ ). We observed a downregulation of genes involved in canonical Erk signaling (ptpn11, raf1, map2k1), downregulation of tsc2 and upregulation of rps6ka, indicating activation of the mTOR pathway. ${ }^{20}$ These data and the fact that EFhd1 increased ppargc1a predicted that EFhd1 expression favors mitochondria as the preferential source of energy, leading to an increase in the OCR/ECAR ratio, but may simultaneously induce an anabolic phenotype, that is, increased ATP consumption and finally exhaustion. ${ }^{20}$

EFhd1 decreases mitochondrial ATP production in pre B cells. To test the hypothesis that EFhd1 alters mitochondrial activity or glycolysis, we performed extracellular flux analyses with a Seahorse device, using WT and EFhd1tg pro and pre B cells. Because of the very limited cell numbers obtainable by cell sorting $\left(\sim 10^{5}\right.$ pro B cells per mouse, with $1.6 \times 10^{6}$ cells needed per mouse per experiment), we had to expand pro $B$ cells using IL-7 ex vivo cultures. We chose an IL-7 concentration where pro B cells do not outnumber pre B cells (Supplementary Figures S4 and S5, related to Figure 6). IL-7 derived pro and pre B cells behaved very similar to directly ex vivo assayed pro and pre $\mathrm{B}$ cells of the Rag1 $^{-1-}$;33.C9 $\mu \mathrm{HCki}$ system (Figure 6; compare Figure 2) since pre B cells were smaller than pro B cells (Figure 1; Supplementary Figure S3). However, pro and pre B cells from IL-7 cultures were in general larger than their freshly isolated counterparts (Supplementary Figure S3). Pre B cells from IL-7 cultures showed also a significant downregulation of glycolysis (ECAR) when compared to pro B cells, yielding a significantly increased OCR/ECAR ratio (Figures $6 a$ and $b$ ). In contrast to the Rag1 ${ }^{-/-} ; 33$.C9 $\mu \mathrm{HCki}$ system, pre B cells from IL-7 cultures exhibit a higher mitochondrial spare capacity (ratio of maximal to basal $\mathrm{O}_{2}$ consumption) than pro $B$ cells from IL-7 cultures (Figure $6 b$ ). Thus, IL-7 does exert major effects on pro and pre $B$ cell metabolism. IL-7 cultures from WT and EFhd1tg mice were comparable in proliferation and differentiation (Supplementary Figures S3 and S4), but freshly isolated WT pro B cells briefly expanded in the absence of IL-7, whereas EFhd1tg pro B cells did not do so at all (Supplementary Figure S4). Ectopic expression of EFhd1 had only minor effects on ECAR and OCR (Figures $6 a$ and b). Unexpectedly, but in line with a competitive disadvantage of EFhd1tg pre B cells, EFhd1 expression resulted in significantly reduced mitochondrial ATP production (Figure 6b). Like in the Rag1/-/33.C9 $\mu \mathrm{HCki}$ system, albeit not to the same extent, mitochondrial coupling efficacy increased slightly from WT pro to pre B cells. However, EFhd1 expression in pre B cells reduced mitochondrial coupling efficacy at the pro to pre B cell transition $(P=0.057)$ (Figures $6 \mathrm{~d}$ and $e)$. Taken together, prolonged expression of EFhd1 in pre B cells distorts mitochondrial ATP production. This was paralleled by a less efficient induction of mitochondrial coupling at the pro to pre B-cell transition.

EFhd1 knockdown decreases the OCR/ECAR ratio in 38B9 cells. Next, we wished to assess the mitochondrial function of EFhd1 in pro B cells independent of IL-7. To this end, we knocked down EFhd1 by an shRNA approach using three different shRNAs that resulted in different knockdown efficacies in the 38B9 pro B-cell line (Figures 7a and b; knockdown efficacy is indicated by a gray color code). We then tested mitochondrial activity and glycolysis by measuring OCR and ECAR. The observed reduction of the OCR/ECAR ratio correlated directly and in a linear manner with reduction of EFhd1 expression (Figures $7 \mathrm{~b}$ and c) and suggested increased glycolytic rates. As knockdown efficacies were low, we established Crispr-Cas9 mediated knockout of EFhd1 (Figure 7e). 38B9 EFhd1 knockout cells revealed trends towards decreased OCR, but significantly increased basal glycolysis, maximal glycolytic capacity and glycolytic reserve (Figures $7 f$ and $g$ ). Consequently, the OCR/ ECAR ratio was reduced ( $P=0.052$, Student's $t$-test). Taken together, we have unraveled for the first time metabolic adaption during early B-cell development and pre-BCRinduced regulatory signals controlling mitochondrial metabolism, ATP synthesis and glycolysis through regulation of the $\mathrm{Ca}^{2+}$-binding mitochondrial protein EFhd1.

\section{Discussion}

Previously, IL-7/CXCL12 cultures of mixed pro/pre B cells from WT and Fnip $1^{-/-}$mice had been analyzed by extracellular flux analysis. ${ }^{20}$ Yet, to our best knowledge, neither a comprehensive comparative metabolic analysis during B-cell development in the BM nor a metabolic analysis of separated primary pro and pre $B$ cells in the absence or presence of IL-7 has been performed so far. We noted that IL-7 has specific effects: It increases mitochondrial spare capacity and it maintains mitochondrial ATP production in cultured small pre B cells. Nevertheless, several results obtained with the Rag1 $1^{-/-} ; 33$. $\mathrm{C} 9 \mu \mathrm{HCki}$ system in the absence of IL-7 were corroborated in IL-7 cultures of pro and pre B cells (decreased ECAR, increased OCR/ECAR ratio in small pre B cells). We demonstrate that small pre $B$ cells downregulate their metabolic activity even when compared to pro B cells, and that large pre B cells are superior in glucose uptake and ROS production. The fact that we observed the most glucose uptake by large pre B cells matches the higher energy demand certainly required in large pre B cells. Increased metabolic activity in large pre $B$ cells might be at least partially driven by the higher glucose consumption. A finding that supports our interpretation of increased metabolic activity in large pre $B$ cells is the increased ROS production in large pre B cells, as ROS is a byproduct of a highly active mitochondrial respiratory 
chain. It is relevant in this respect that downregulation of EFhd1 in 38B9 pro B cells, normally achieved by surface pre BCR expression, increases glycolytic parameters. The downregulation of EFhd1 by the pre BCR represents therefore one possible mechanism of how the pre BCR increases metabolic activity in large pre B cells. Our extracellular flux analysis of primary pro and small pre B cells missed large pre B cells due to technical reasons. Large pre B cells may in the future be enriched from Irf4/8 double or BLNK/SLP-65 knockout mice. To sum up, it is tempting to speculate that increased aerobic glycolysis occurs in large pre B cells through downregulation of EFhd1, providing more energy and more anaplerotic a

ebf1

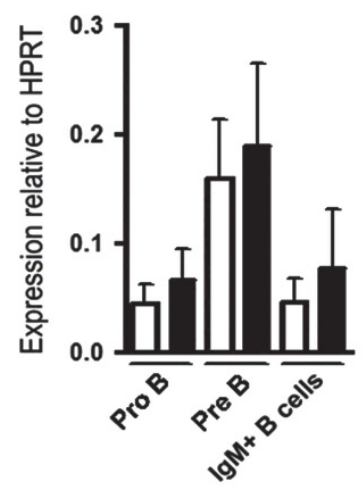

ucp2
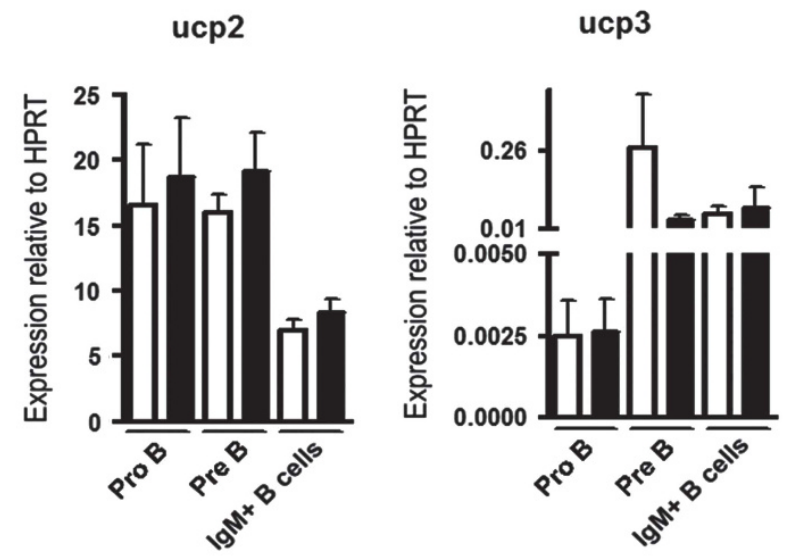

C
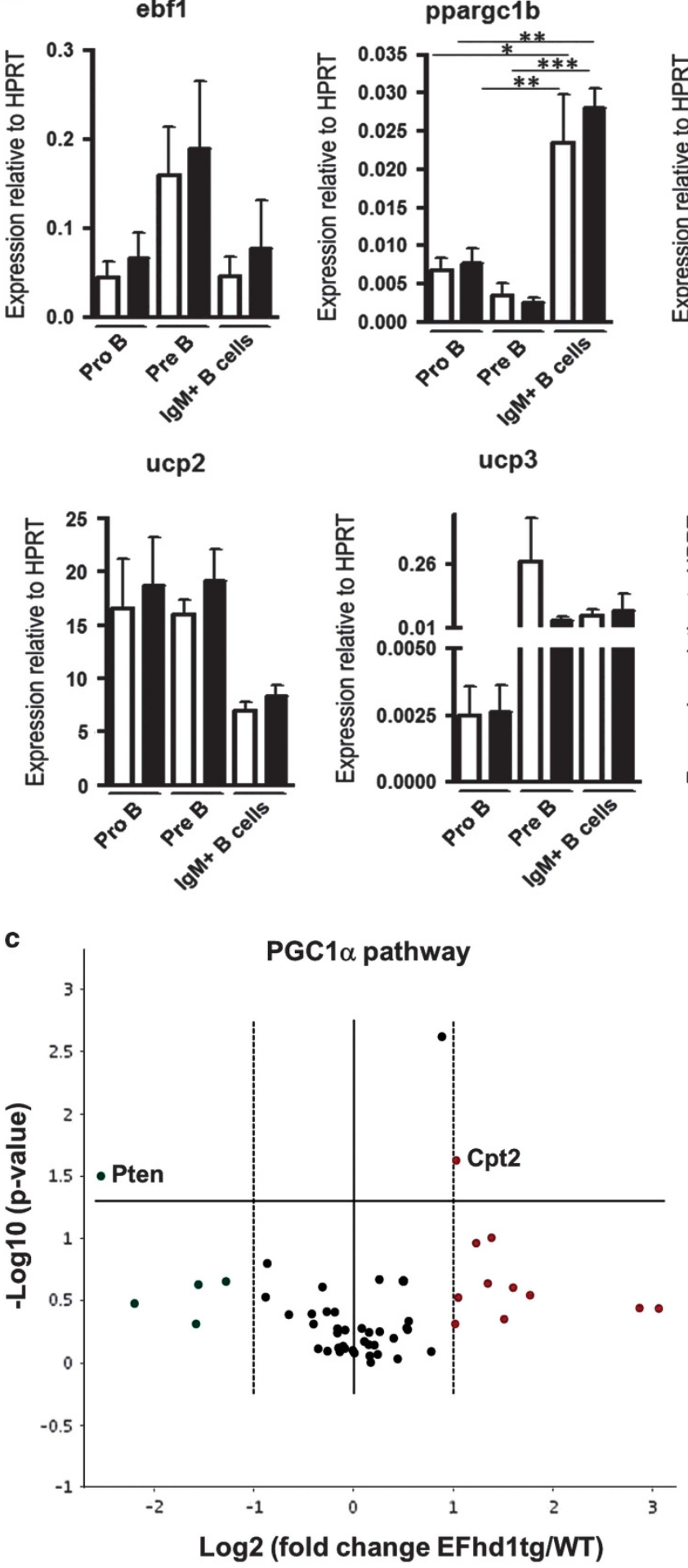

ucp3

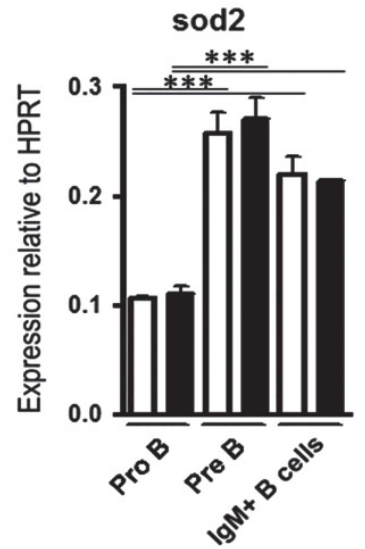

d
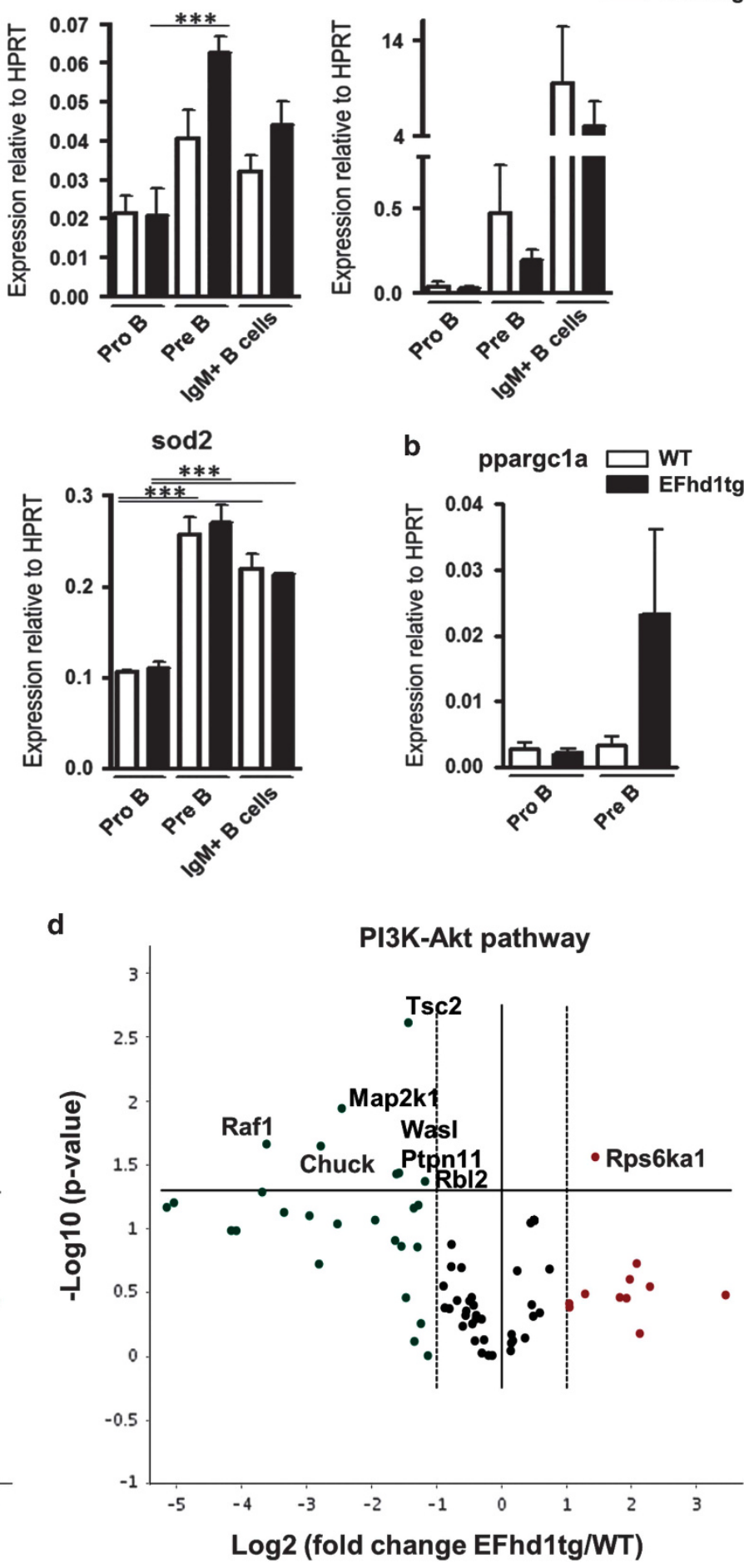

I3K-Akt pathway

glut1

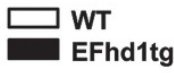


reactions for macromolecules and intermediate products protecting from ROS. ${ }^{45}$ Glucose uptake dropped in small pre $B$ cells, even below the level of pro B cells. In full accordance, we measured a decline of ECAR in small pre B cells as compared to pro $\mathrm{B}$ cells. The PI3K/Akt pathway regulates glycolysis positively and is an important regulator of B-cell differentiation. ${ }^{12}$ Thus, the decrease of glycolysis (as defined by ECAR) in small pre B cells compared to pro B cells is in accordance with inactivation of the Akt pathway and may implement nuclear commands signaling transient quiescence. ${ }^{13,46}$ Vice versa, increased glycolysis in 38B9 EFhd1 knockout pro B cells may comprise a mechanism of early pre BCR signaling, leading normally to downregulation of EFhd1. We observed downregulation of glucose uptake, $\Delta \psi \mu$ and ROS generation in small pre B cells. Together with Pax5, FOXO1 transactivates Rag1/2, IRF4 and p27 that induces cell cycle arrest while LC rearrangement takes place in small pre $B$ cells. ${ }^{28,39,47} \mathrm{FOXO1}$ is also activated by ROS and upregulates superoxide dismutase 2 (sod2). ${ }^{40}$ The increase in the FOXO1 target gene, sod2, in pre B cells is compatible with an induction of FOXO1 through inactivation of $\mathrm{Akt}^{40}$ and might limit ROS. Although small pre $B$ cells reduced both glycolysis (ECAR) and OxPhos (OCR), ECAR was in relation reduced more. These observations were congruent in pre $\mathrm{B}$ cells from both the 33.C9 $\mu \mathrm{HC}$ system and from WT IL-7 cultures. Our interpretation is that pro $\mathrm{B}$ cells rely more on aerobic glycolysis for energy production than small pre B cells. OxPhos often takes over in cells differentiating away from stem cells. ${ }^{48}$ The shift towards a more mitochondrial metabolism in small pre $B$ cells is therefore in line with their advanced differentiation status. In line, we uncovered that the mitochondrial coactivator PGC-1a ${ }^{49}$ is increased in pre B cells. We have uncovered a causative relation between EFhd1 and PGC-1a: EFhd1tg pre B cells show significantly increased PGC-1a expression. In accordance, they revealed a slightly increased OCR/ECAR ratio, with knockout of EFhd1 in the pro B-cell line 38B9 showing the opposite. Although PGC-1a stimulates mitochondrial biogenesis, ${ }^{49}$ we did not observe increased mitochondrial mass in EFhd1 expressing pre B cells (unpublished data). It is possible that EFhd1 blocks another co-factor required for this function of PGC-1a, which might also explain why not many PGC-1- $a$ target genes are upregulated by EFhd1. Interestingly, EFhd1 interacts in mitochondria with the estrogen receptor alpha chain (esr1, nr3a1) and there are numerous studies about the bidirectional interdependence of Esr1 and PGC-1a.$^{50}$ EFhd1 could therefore impact expression of PGC-1 $a$ and its target genes via Esr. Given that
PGC-1a upregulation is expected to support mitochondrial metabolism, why then does EFhd1 counteract mitochondrial ATP production in pre B cells? One interpretation could be that the normal downregulation of EFhd1 in pre B cells prevents ATP exhaustion perhaps by generation of ATP via glycolysis. Increased rps6ka1 expression induces anabolic ATP exhaustion in Fnip $1^{-1-}$ pro/pre B cells and also in $\mathrm{PTEN}^{-1+}$ and $\mathrm{PTEN}^{-1-}$ pre B ALL cells. ${ }^{20,51}$ Hence, the regulation of the pten/tsc2/rps6ka1 axis may exaggerate the disadvantage of EFhd1tg pro and pre B cells in vivo. Pre B cells face heavy selection pressure for an optimal pre BCR signaling strength. ${ }^{1}$ EFhd1tg pre B cells would therefore represent pre B cells where the pre BCR has induced only insufficient signals to mediate downregulation of EFhd1, such as intracellular $\mu \mathrm{HC}$ that are unable to pair with the surrogate LC, do not provide optimal signals ${ }^{52}$ and cannot downregulate EFhd1. Through EF hand mediated $\mathrm{Ca}^{2+}$ binding, ${ }^{31}$ EFhd1 positively regulates mitoflashes under conditions of high intracellular $\mathrm{Ca}^{2+}$. The alkalinization of the mitochondrial matrix during a mitoflash may reduce the efficacy of mitochondrial ATP production. ${ }^{32}$ EFhd1 might therefore translate the pre BCR-elicited increase in $\mathrm{Ca}^{2+}$ into mitoflashes, ${ }^{5}$ compromising ATP generation. We propose that downregulation of EFhd1 represents a sensor of optimal pre $\mathrm{BCR} \mathrm{Ca}^{2+}$-signaling strength governing $\mu \mathrm{HC}$ selection in the BM. Taken together, an intimate interplay of pre $\mathrm{BCR}$ controlled genes involved in metabolism and $\mathrm{Ca}^{2+}$ sensing, such as efhd1, appears to be important for fitness of early $B$ cells.

\begin{abstract}
Materials and Methods
Mice, BM transfer and B cell homing. A transgene expression cassette, pBSVE6BK (kind gift of Dr. Carlo Croce) with blunt-end EcoRV inserted murine EFhd1 cDNA under control of $\mathrm{V}_{\mathrm{H}}$ promoter (V186.2), and $\mathrm{E} \mu$-enhancer ${ }^{53}$ was linearized and injected into the pronucleus of C57BI/6 zygotes. Offspring was characterized with the following PCR primers and conditions (fwd $5^{\prime}$-GAA CTTCTTCGAAGCCAA-3' and rev 5'-ATGACATGAACTTAACCATA-3'; $94^{\circ} \mathrm{C}$ for $5 \mathrm{~min} ; 35$ cycles $\left(94^{\circ} \mathrm{C}, 30 \mathrm{~s} / 60^{\circ} \mathrm{C}, 30 \mathrm{~s} / 72{ }^{\circ} \mathrm{C}, 1 \mathrm{~min}\right)$. Southern blot analysis was used to quantify integrated transgene copies using a $292 \mathrm{bp}$ probe representing complete efhd1 exon1. The insertion site of the transgene was mapped by digestion of genomic DNA with Msp1, religation and PCR with primers E $\mu$ fwd (5'-ttg gtggggctggacagag-3'), E $\mu$ rev (5'-ACCGAAAGTCCAGGCTGAGC-3'), $\beta$ Globfwd (5'-TTTTATGGTTGGGATAAGGCTG- $3^{\prime}$ ) and $\beta$ Globrev ( $5^{\prime}$-GCAGAATGGTAGCT GGATTG-3'). PCR products were cloned, sequenced and insertion points were identified by BLAST. Mice were maintained in IVC cages. Animal experiments were conducted according to institutional ethical guidelines for animal of the FriedrichAlexander-University (FAU) Erlangen-Nuremberg and approved by the state of Bavaria. Unless stated otherwise, 6-20-week-old littermates of both sexes were used. C57B//6/Ly5.1 (B6.SJL-Ptprca Pep3b/BoyJ) mice were originally obtained from the Jackson Laboratory. 33.C $\mu \mathrm{HCki}$ mice were generated by homologous
\end{abstract}

Figure 5 Expression of metabolic and mitochondrial genes in BM B lymphocyte subsets. (a) BM was isolated from EFhd1tg and WT mice and pro B (CD19 ${ }^{+}, \mathrm{cKit}^{+}$, CD25 slgM $\left.{ }^{-}\right)$, pre B cells $\left(\mathrm{CD} 19^{+}, \mathrm{CKit}^{-}, \mathrm{CD}^{+} 5^{+}, \mathrm{slgM}^{-}\right)$and BCR+ B cells $\left(\mathrm{CD} 19^{+}, \mathrm{CD}^{-} 5^{-}, \mathrm{CKit}^{-}\right.$, slgM $\left.{ }^{+}\right)$were sorted by FACS. RNA was isolated, and converted into $\mathrm{CDNA}$. Expression of ebf1, ppargc1a, ppargc1b, glut1, ucp2, ucp3 and sod2 was evaluated by SYBR Green qPCR, analyzed with the $\triangle \Delta C T$ method and normalized to hprt. mRNA expression of is represented as mean \pm S.E.M. of three independent experiments and was tested for statistical significance by ANOVA with Bonferroni correction for multiple testing, (b) RNA was isolated from sorted pro $\left(\mathrm{CD}^{2} 9^{+}, \mathrm{cKit}^{+}\right.$, slgM $\left.{ }^{-}\right)$and pre $\mathrm{B}\left(\mathrm{CD} 9^{+}, \mathrm{cKit}^{-}\right.$, slgM $\left.{ }^{-}\right)$of EFhd1tg and WT mice after 7 days culture with $5 \mathrm{ng} / \mathrm{ml}^{\mathrm{IL}-7}$. RNA was converted to CDNA and ppargc1a (PGC-1 $\alpha$ ) expression was analyzed as described in (a). Data is represented as mean+S.E.M. of four independent cultures and sorts per genotype and statistical analysis was carried out by Mann-Whitney- $U$ test. (c and d) RNA was isolated from pre B cells $\left(\mathrm{CD}_{1} 9^{+}, \mathrm{cKit}^{-}, \mathrm{CD}^{2} 5^{+}\right.$, slgM $\left.{ }^{+}\right)$sorted from EFhd1tg and WT BM. cDNA conversion and expression profile analysis were carried out by Qiagen Mouse PPAR Targets (a) or (b) PI3K-Akt pathway RT ${ }^{2}$ Profiler PCR Array. Data was analyzed with the available online software (www.SABiosciences.com/pcrarraydataanalysis.php). Normalization was carried out by an automatic algorithm against suitable genes of the whole plate. The data are represented as heat map and volcano plot of Log2 fold change in gene expression of EFhd1tg to WT pre B cells against - Log10 of the $P$-value. Values represent the mean of three EFhd1tg against three WT mice 
a

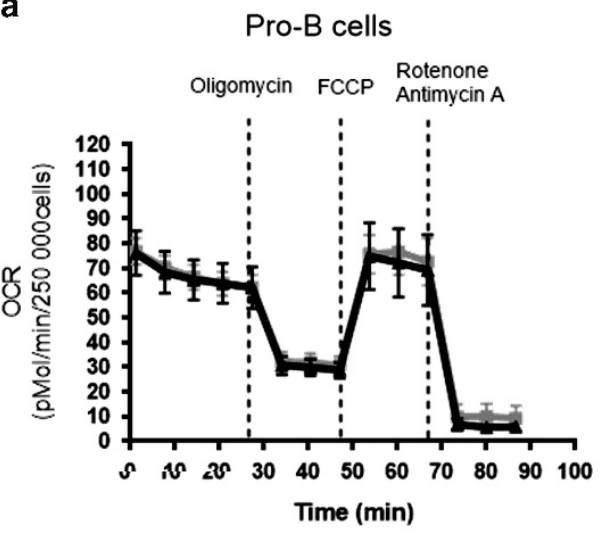

b
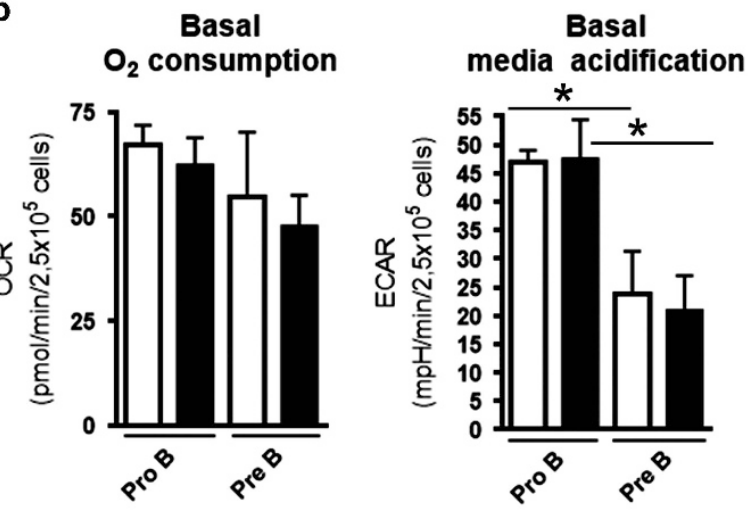

Mitochondrial ATP production

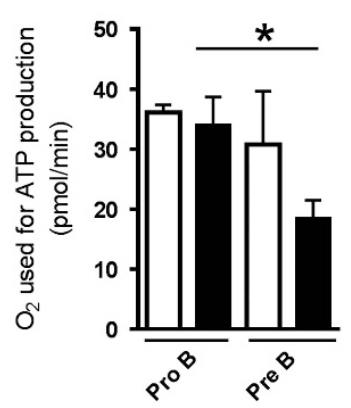

Proton leak

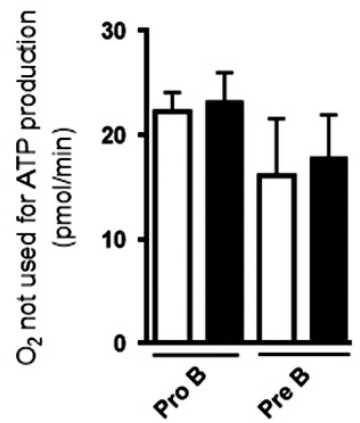

Pre-B cells Oligomycin FCCP $\begin{aligned} & \text { Rotenone } \\ & \text { Antimycin A }\end{aligned}$

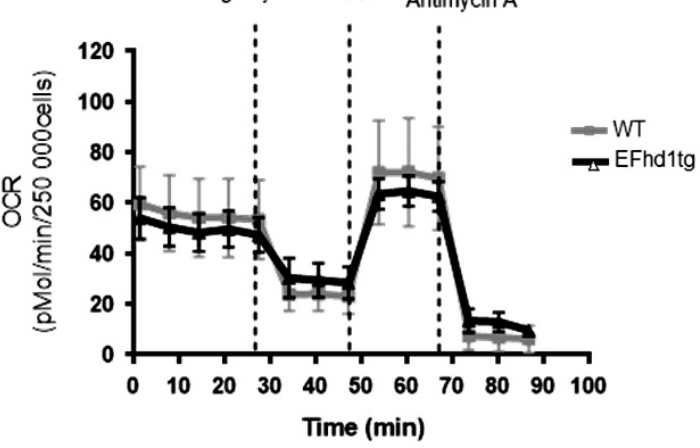

Spare capacity for phenotype profile

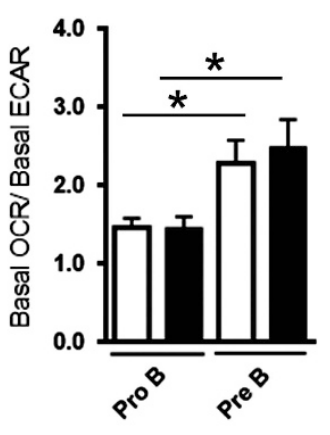

Non mitochondrial respiration

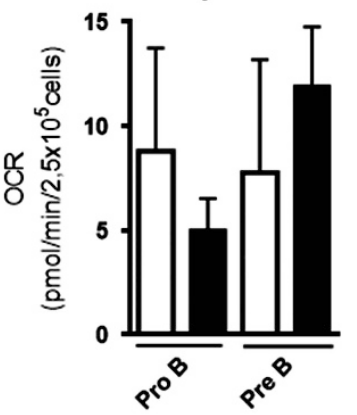

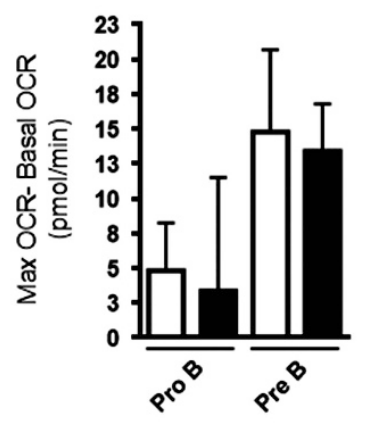

Coupling efficiency

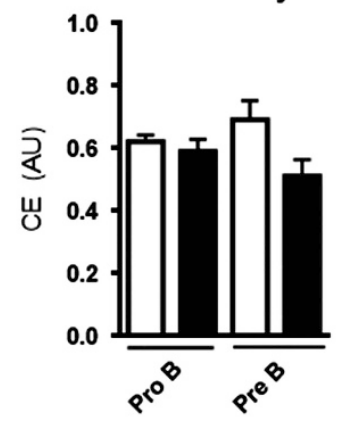

Figure 6 Metabolic profile of EFhd1tg and WT IL-7 pro B cell cultures. (a) Sorted pro B cells were cultured with $5 \mathrm{ng} / \mathrm{ml} \mathrm{IL-}^{-7}$. After 7 days, pro (CD19+ cKit $^{+}$, slgM ${ }^{-}$) and pre B $\left(\mathrm{CD} 9^{+}, \mathrm{cKit}^{-}\right.$, slgM $\left.{ }^{-}\right)$cells were sorted and metabolic activity of pro and pre B cells from the IL-7 culture was directly determined by Mito Stress Test with a Seahorse XF ${ }^{\mathrm{e}} 96$ analyzer. Five basal readings were taken for oxygen consumption rate $(\mathrm{OCR})$ and basal extracellular acidification rate (ECAR). The results are represented as mean \pm S.E.M. Three readings were taken after complex V (ATPase) inhibition by oligomycin and three readings for maximum OCR were taken after addition of the mitochondrial uncoupler FCCP. (b) An energy phenotype of the cells is calculated by dividing OCR by ECAR. Spare capacity (the increase from basal to maximum OCR) and the mitochondrial ATP production rate (the OCR which can be blocked by adding ATPase inhibitor oligomycin) are shown as bar diagrams. Mitochondrial proton leakage, (OCR which can be further blocked by antimycin $A$ and rotenone after oligomycin administration) and non-mitochondrial respiration (OCR remaining after fully blocking the mitochondria with oligomycin, antimycin $A$ and rotenone) were calculated. The coupling efficiency represents the ratio of mitochondrial ATP production and proton leak. Data are represented as mean \pm S.E.M. of four independent sorts and seahorse experiments of each time three pooled EFhd1tg and WT mice. Statistical analysis was done by ANOVA with Bonferroni correction for multiple testing

recombination in V6.5 embryonic stem cells. The $\mathrm{HC}$ variable region of the hybridoma $33 . \mathrm{C} 9$ backmutated to its germ line sequence ${ }^{54}$ was inserted into the targeting vector pIVHL2neo kindly provided by Roberta Pelanda. ${ }^{55}$ Heterozygous knock-in mice were backcrossed to C57BI/6 für 12 generations and mated with Rag1 $1^{-1-}$ mice obtained from Irmgard Förster (University Munich). Rag2 ${ }^{-1-} \mathrm{dTg}$ $(\mathrm{lg}$-tTA/tet- $\mu)$ mice were treated for 7 days with tetracycline in the drinking water as described previously. ${ }^{6}$ For mixed BM chimeras, C57B//6/Ly5.1 or C57B//6/L5.2 mice were irradiated with one dose of 6 Gy and one dose of 5 Gy given $4 \mathrm{~h}$ apart, followed by i.v. reconstitution with a $1: 1 \mathrm{mix}$ of $2 \times 10^{6} \mathrm{BM}$ cells in PBS prepared from the femurs of C57BI/6 Ly5.1 and C57BL76 EFhd1tg/Ly5.2, or C57BI/6/Ly5.1 and C57BI/6 WT Ly5.2 mice. Recipients were analyzed after 6 weeks reconstitution. For B-cell homing, non-irradiated recipient mice were injected i.v. with a $1: 1 \mathrm{mix}$ of $2 \times 0^{7}$ WT B cells labeled with CSFE (eBioScience)/EFhd1tg B cells labeled with eF670 (eBioScience) I (or vice versa) in PBS. B cells were isolated by CD43 


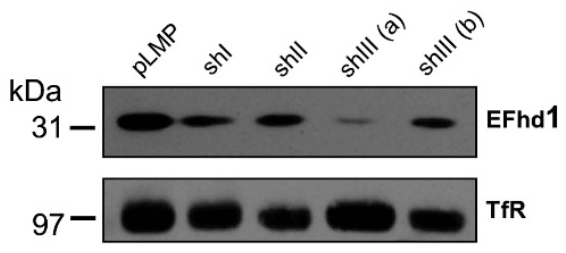

d

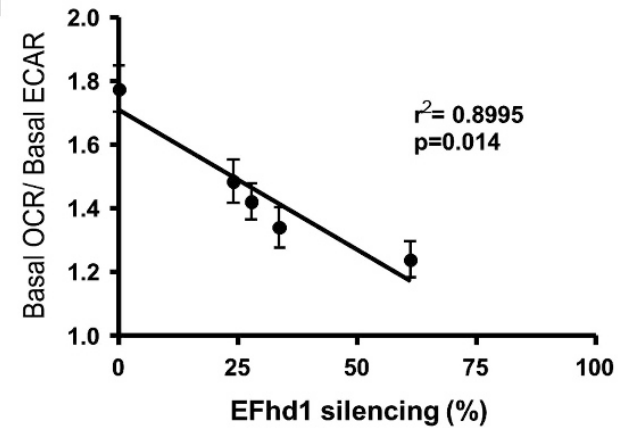

f

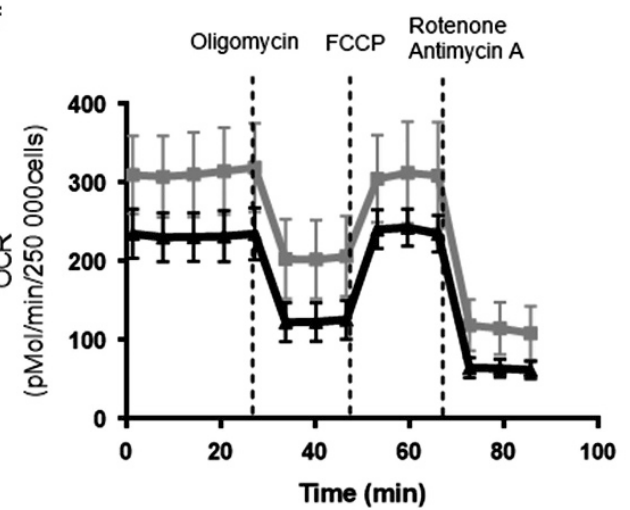

- 38B9 WT (B4, D6, E8)

- 38B9 KO (C9, D7, E7) b

อ
$\frac{5}{0}$
$\frac{0}{6}$
$\frac{0}{6}$
$\frac{5}{4}$
$\frac{5}{4}$

号

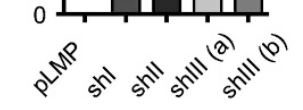

0

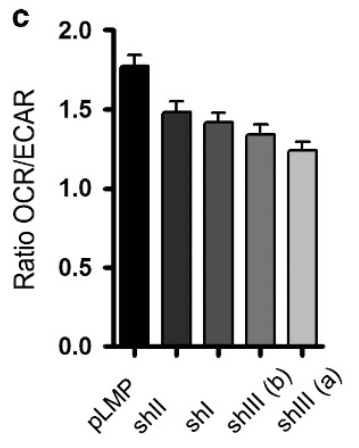

e

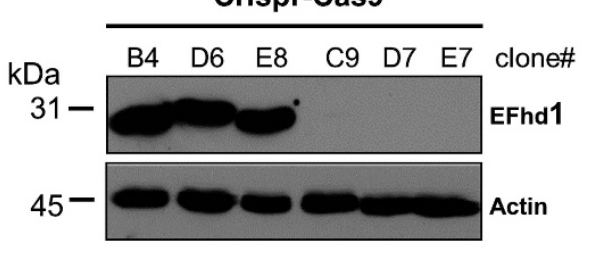

g

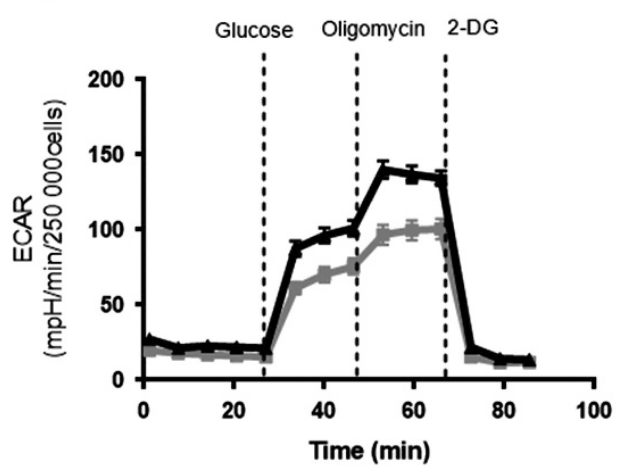

- 38B9 WT (B4, D6, E8)

- 38B9 KO (C9, D7, E7)

h
Basal i
i Basal media acidification j due to glycolysis
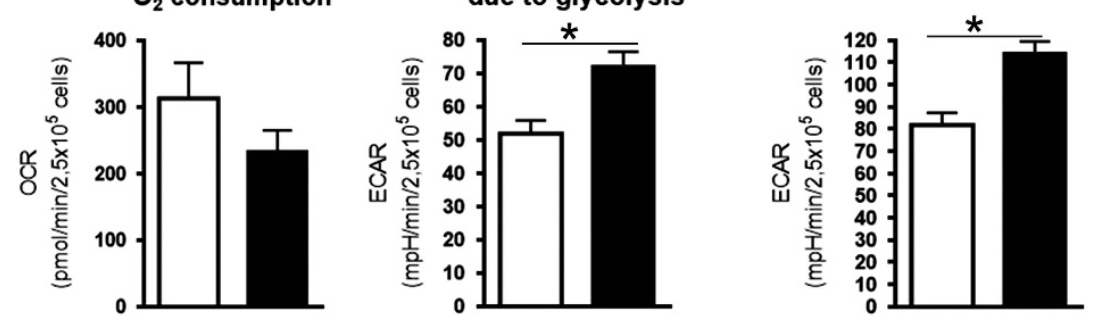

k

Glycolytic reserve

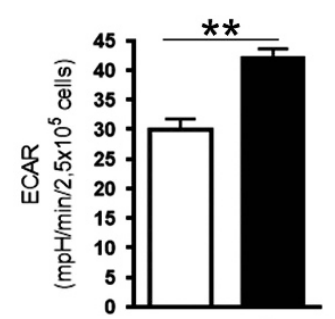

Figure 7 Metabolic profile of 38B9 pro B-cell lines with shRNA-mediated EFhd1 knockdown. (a) 38B9 cells stably transfected with pLMP and four stable knockdown cell lines were analyzed for EFhd1 protein expression by western blot, Molecular mass standards are indicated on the left $(\mathrm{kDa})$. (b) EFhd1 expression was normalized to TfR protein expression and represented as mean percentage \pm S.E.M. in comparison to $\mathrm{pLMP}, n=3$, (c) The metabolic activity of the $38 \mathrm{~B} 9$ cell lines was analyzed by Mito Stress Test with a Seahorse XF analyzer. Basal OCR, as well as the basal ECAR and the cell energy phenotype profiles (OCR/ECAR) are represented as mean \pm S.D. of three to five measurements, (d) Correlation of the percentage of EFhd1 silencing with the cells' energy phenotype profile (OCR/ECAR), (e) Western blot analysis of Crispr-Cas 9 engineered 38B9 EFhd1 knockout and control clones, (f) Mitochondrial activity of of randomly chosen 38B9 WTand EFhd1 knockout clones was analyzed by Mito Stress Test with a Seahorse $\mathrm{XF}^{\mathrm{e}} 96$ extracellular flux analyzer. Five readings were taken for basal oxygen consumption rate (OCR) before subsequent addition of oligomycin, FCCP and antimycin+rotenone, (g) Glycolytic activity of randomly chosen 38B9 WT and EFhd1 knockout clones was analyzed by Glyco Stress Test with a Seahorse XF 96 extracellular flux analyzer. Five readings were taken for basal ECAR in glucose-free medium before subsequent addition of glucose, oligomycin and 2-deoxyglucose (2-DG), (h) Basal $\mathrm{O}_{2}$ consumption from Mito stress test, (i) Basal media acidification (glycolysis stress test), (j) Maximal glycoloytic capacity after addition of glucose (glycolysis stress test), (k) Maximal glycoloytic capacity after addition of oligomycin (glycolysis stress test). Statistical analysis was done with Student's $t$-test 
depletion (Milteny, Bergisch-Gladbach, Germany). BM, spleen and inguinal LN were analyzed either after $3 \mathrm{~h}$ or $24 \mathrm{~h}$ post injection for CSFE and eF670 positive viable lymphocytes.

Antibodies and chemicals. All chemicals were purchased from SigmaAldrich (Taufkirchen, Germany), Merck (Darmstadt, Germany) or Roth (Karlsruhe, Germany) unless stated otherwise. Cell culture medium and medium supplements were obtained from Invitrogen LifeTechnologies. Antibodies were purchased from BD Pharmingen (Heidelberg, Germany), BioLegend (London, England), eBioscience (Dreieich, Germany), Jackson ImmunoResearch Laboratories (distributed by Dianova, Hamburg, Germany) unless stated otherwise. The following antibodies were used for flow cytometry and cell sorting: unconjugated antiCD16/32 (FC Block; 93; eBioscience), Alexa fluor 647 (AF647)-conjugated CD19 (eBio1D3; eBioscience), CD2 phycoerythrin (PE)-conjugated anti-CD19 (eBio1D3; eBioscience), Brilliant Violet 421 (BV)-conjugated anti-CD19 (BioLegend), fluorescein (FITC)-conjugated anti-CD21/35 (CR2/CR1; eBio8D9; eBioscience), FITC-conjugated anti-CD23 (eBioscience), PE-conjugated anti-CD23 (FceRll; B3B4; eBioscience), APC-conjugated anti-CD25 (PC61; BioLegend), FITCconjugated anti-CD43 (Ly-48, S7; BD), peridinin-chlorophyll protein-cyanine5.5 (PerCP)-conjugated anti-CD45R (B220; eBioscience), PE-conjugated anti-CD117 (c-kit; ACK45; BD), APC-conjugated anti-CD117 (c-kit, eBioscience), BV 421conjugated anti-CD117 (c-kit, eBioscience), PerCP-Cy5.5-conjugated antiCD45.2 (eBioscience), Pacific Blue (PB)-conjugated anti-CD45.1 (BioLegend), Biotinconjugated anti-lgD (Southern Biotech, distributed by Biozol, Eching, Germany), FITC-conjugated anti-IgM (Southern Biotech, distributed by Biozol, Eching, Germany), and Cyanine (Cy)5-conjugated anti-IgM (Southern Biotech); to detect biotinylated antibodies, PerCP-conjugated streptavidin (BD) were used.

FACS analysis. A total of $0.5-2 \times 10^{6}$ cells were washed with $500 \mu \mathrm{l}$ FACS buffer ( $2 \% \mathrm{FCS} / 0.01 \% \mathrm{NaN}_{3} / \mathrm{PBS}$ ), resuspended in $100 \mu \mathrm{l}$ antibody staining solution (FACS buffer with primary antibodies) for $20 \mathrm{~min}$ at $4{ }^{\circ} \mathrm{C}$ in the dark, washed and if required stained with secondary antibodies and kept on ice until measurement. For intracellular analysis, cells were fixed and permeabilized according to manufacturer's instructions (von der Grub). Data were acquired on a FACSCalibur (BD) or Gallios flow cytometer (Beckman Coulter, Krefeld, Germany), and analyzed with the Kaluza (Beckman coulter, Version 1.2) or FlowJo software (Version 8.8.7, Ashland, OR, USA). To determine cell numbers by flow, cells were resuspended in $250 \mu \mathrm{l}$ FACS buffer and $10 \mu \mathrm{l}$ Coulter CC size standard L10 (Beckman Coulter, \#B01828-AA) in PBS with a known concentration of beads (3$5 \times 10^{5}$ beads per $\mathrm{ml}$ ).

Mitochondrial and metabolic stains. Cells were washed once in unsupplemented OptiMEM medium and then incubated for $30 \mathrm{~min}$ at $37^{\circ} \mathrm{C}, 5 \%$ $\mathrm{CO}_{2}$ in the same medium with either $10 \mathrm{nM}$ MitoTracker Green FM (Cell signalling \#9074S, Frankfurt, Germany), $25 \mathrm{nM}$ tetramethylrohdamine (TMRM) (Life Technologies, Dreieich, Germany, \#T668) in the absence or presence of $100 \mu \mathrm{M}$ carbonyl cyanide 3-chlorophenlyhydrazon (CCCP) or $1 \mu \mathrm{M}$ DCFDA (Sigma, Taufkirchen, Germany). Fluorescence of CCCP-treated cells was subtracted to obtain specific TMRM signals. Cells were washed with unsupplemented OptiMEM and afterwards stained for surface markers as described in the previous section, but in OptiMEM medium. To measure glucose uptake, the cells were stained with $300 \mu$ M 6-NBDG (Life Technologies, \#N23106) in glucose-free medium and washed in the same.

Cell isolation and cell sorting. Splenic cells were isolated by passing the organ through a $70 \mu \mathrm{m}$ nylon filter. Splenic B cells were isolated to a purity of routinely $>92 \%$ with an EasySep Mouse B cell isolation negative selection kit (EasySep \#19854A) according to the manufacturer's instructions. The cells were cultured in R10 $0^{+}$medium (RPMl 1640 medium (Gibco-Invitrogen, Dreieich, Germany) supplemented with $10 \% \mathrm{v} / \mathrm{v}$ fetal calf serum (FCS; Gibco-Invitrogen, heat inactivated at $56{ }^{\circ} \mathrm{C}$ for $45 \mathrm{~min}$ ), $2 \mathrm{mM}$ glutamate, $1 \mathrm{mM}$ sodium pyruvate, $50 \mathrm{U} / \mathrm{ml}$ penicillin $\mathrm{G}, 50 \mu \mathrm{g} / \mathrm{ml}$ streptomycin and $50 \mu \mathrm{M} \beta$-mercaptoethanol) at $37^{\circ}$ $\mathrm{C}, 5 \% \mathrm{v} / \mathrm{v} \mathrm{CO}_{2}$ ) with further additions as indicated. BM cells were isolated by flushing the bones with a G23 needle with cold OptiMEM10 medium (OptiMEM medium (Gibco-Invitrogen) with the same additions as R10+ medium). Rag1 ${ }^{-1-}$ and Rag1 ${ }^{-1} ; 33$.C9 $\mu \mathrm{HCki} B$ cells were isolated by Mouse CD19-positive selection kit (EasySep, Stem cell technologies, Köln, Germany, \#18754). Pro B cells (CD19+,

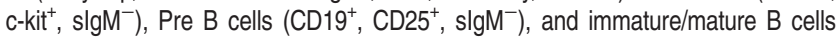
$\left(\mathrm{CD}_{19}+, \mathrm{IgM}^{+}\right)$were sorted by MoFlo (Beckman Coulter, Krefeld, Germany) or
Astrios (Beckman Coulter, Krefeld, Germany) to a purity $>95 \%$ into medium or directly into RLT buffer (Qiagen kit) for RNA extraction. Pro B cells from IL-7 cultures were sorted as $\mathrm{CD} 19^{+}$, $\mathrm{CKit}^{+}$, slgM ${ }^{-}$, pre B cells $\mathrm{CD} 19^{+}$, $\mathrm{CKit}^{-}$, slgM ${ }^{-}$and immature $\mathrm{B}$ cells as $\mathrm{CD}_{19^{+}}$, $\mathrm{CKit}^{-}$, $\mathrm{slgM}^{+}$.

Confocal microscopy. B cells were positively sorted from the BM of Rag1 ${ }^{-1}$ - or Rag1 $1^{-1} ; 33$.C9HCki mice with anti-CD19 magnetic beads and attached to slides. Cells were stained with TMRM (100 nM) and anti-CD19 antibody coupled to FITC in the absence or presence of CCCP $(100 \mu \mathrm{M})$, washed in OptiMEM and covered with cover slips. Images were taken along the central plane of cells. (Zeiss LSM700 (Oberkochen, Germany), $63 \times$ oil objective, $90 \mathrm{~nm}$ voxel size, eightfold averaging, 16 bit image depth).

Pro B-cell culture. Pro B cells were seeded at $10^{5}$ cells per $\mathrm{ml}$ and cultured in OptiMEM medium supplemented with $10 \%$ v/v FCS (Gibco-Invitrogen, heat inactivated at $56{ }^{\circ} \mathrm{C}$ for $45 \mathrm{~min}$ ), with IL-7 (Peprotech, Hamburg, Germany, \#217-17) as indicated. IL-7 was added freshly every 3 days, new medium added on day 4 and the cells split to original density on day 5 . To analyze proliferation, freshly sorted pro B cells were labeled with eFlour 670 (eBioscience) according to manufacturer's instructions.

Retroviral infection of cells. Three commercially available shRNAS directed against murine EFhd1 and a control (Biocat, Heidelberg, Germany) were cloned into the retroviral vector pLMP (GE healthcare, Dornstadt, Germany; please note that EFhd1 shRNA-targeting sequences were not published and not available on demand from the distributor; shRNAS directed against EFhd1 are therefore numbered 1-3). Retroviral particles from the pLMP constructs were produced as described previously, ${ }^{34}$ 38B9 cells $^{25}$ were infected according to standard procedures $^{34}$ and selected with $5 \mu \mathrm{g} / \mathrm{ml}$ puromycin. The pCHIG (CMV promoter $\mu \mathrm{H}$ chain IRES-GFP) retroviral vectors expressing $\mu \mathrm{HC}$ were constructed as follows: $V_{H}$ fragments were generated by PCR from cDNA of C57B//6 splenic B cells using degenerate primers $\left(V_{H}\right.$ deg fwd: $5^{\prime}$-aggtsmarctgcagsagtcwgg- $3^{\prime}, J_{H}$ deg rev: 5'-TTTGGGAAGCTTTGACTCTCTGAGGARACGGTG-3'; M: A/C, R: A/G, S: C/G, W: $A / T$ ), cloned into PCR2.1 (Invitrogen, Dreieich, Germany) and sequenced. Specific $V_{H}$ fragments $(17.2 .25,31,81 \mathrm{X})$ were then cloned into Sall/Hindlll digested LXSPstar-81XBC2 $\mu \mathrm{m} .^{56}$ The resulting vector containing a complete $\mu \mathrm{HC}$ including $V_{H}$ leader was then used as PCR template to generate a $181 \mathrm{bp}$ fragment of the $V_{H}$ region containing a $5^{\prime}$ Xhol and a $3^{\prime}$ EcoRl site, and to generate an EcoRI/Nlotl fragment. The Xhol/EcoRI digested PCR product and the EcoRI/Notl fragment were then co-ligated with the Xhol/Nhel digested retroviral vector $\mathrm{pClG} / \mathrm{pCru} 5$ containing an IRES-GFP cassette. ${ }^{34}$ Retroviral particles were produced as described previously. ${ }^{34}$ IL-7-dependent R5B cells (kind gift of Dr. Chris Paige) ${ }^{57}$ and 38B9 cells ${ }^{25}$ were infected according to standard procedures ${ }^{34}$ and sorted by means of GFP expression.

Western blot. Western blot analyses were performed according to standard procedures as previously described using rabbit anti EFhd1 $1{ }^{26}$ rabbit anti Actin (Sigma) and mouse anti Transferrin receptor antibodies (Thermo Scientific, Dreieich, Germany), followed by horseradish-peroxidase coupled secondary antibodies and development by enhanced chemiluminescence. Goat anti $\mu \mathrm{HC}$ coupled to horseradish-peroxidase was purchased from Southern Biotech.

RT-PCR. RNA was isolated with the help of a QIAshredder (Qiagen, \#79654) and RNeasy Mini kit (Qiagen, \#74104). 50-100 ng cDNA was transcribed from isolated RNA with the RevertAid First Strand cDNA Synthesis Kit (Thermo Scientific, \#K1622) using oligo(dT)18 primers according to the manufacturer's instructions or the QuantiTect Reverse Transcription kit (Qiagen, \#205311) according to the manufacturer's instructions. Primers were: efhd1: fwd 5'-CGGACTCCGAAC TGAACCTC-3', rev 5'-AACTCCGGGAACTCGGTGTA-3', hprt fwd 5'-TCAGTCA ACGGGGGACATAAA-3', rev 5'-GGGGCTGTACTGCTTAACCAG-3', sod2: fdw 5'-CAGACCTGCCTTACGACTATGG-3', rev 5'-CTCGGTGGCGTTGAGATTGTT-3', ppargc1a: fwd 5'-TATGGAGTGACATAGAGTGTGCT-3', rev 5'-CACTTCAATCCAC CCAGAAAG-3', ppargc1b: fwd 5'-CGCTCCAGGAGACTGAATCCAG-3', rev 5'CTTGACTACTGTCTGTGAGGC-3', upc2: fwd 5'-GCATCCAACGGAGTGGAAG-3', rev 5'-GATTTCCGCAGGTTAGAAGGC-3', ucp3: fwd 5'-CTGCACCGCCAGATG AGTTT-3', rev 5'-ATCATGGCTTGAAATCGGACC-3', ebf1 gene: fwd: 5'-GCAT CCAACGGAGTGGAAG-3', rev 5'-GATTTCCGCAGGTTAGAAGGC-3', glut1: fwd: 5'-CAGTTCGGCTATAACACTGGTG-3', rev 5'-GCCCCCGACAGAGAAGATG-3' (Harvard Primer Bank ${ }^{58}$ ). The qRT-PCR was carried out in triplicate samples with 
$7.5 \mu \mathrm{l}$ SYBRgreen MIX (Applied Biosystems, Life Technologies \#4309155) $1 \mu \mathrm{l}$ (1-5 ng) cDNA/RNA template, $0.25 \mu \mathrm{l}(5 \mu \mathrm{M})$ fwd/rev primer and $6 \mu \mathrm{l}$ ultra-pure $\mathrm{H}_{2} \mathrm{O}$ (Sigma-Aldrich, \#HN68.2) per reaction. The DNA was melted at $95{ }^{\circ} \mathrm{C}$ for $15 \mathrm{~min}$ and heated for $30 \mathrm{~s}$ at $95^{\circ} \mathrm{C}$ and $30 \mathrm{~s}$ at $60{ }^{\circ} \mathrm{C}$ for 40 cycles in an Applied Biosystems 7300 cycler and analyzed by $\Delta \Delta C T$ method. Non reversely transcribed RNA with HPRT primers and $\mathrm{CDNA}$ with $\mathrm{H}_{2} \mathrm{O}$ were included as quality control for each plate. RT $^{2}$ profiler PCR arrays (Qiagen, Mouse PI3K-AKT, \#PAMM-0582F-6 or Mouse PPAR Targets, \#PAMM-149ZA-6) were carried out according to the manufacturer's instructions with $\mathrm{RT}^{2}$ SYBR Green qPCR Mastermix (Qiagen, Hilden, Germany, \# 330510) in an Applied Biosystems (Dreieich, Germany) 7300 cycler after generation of cDNA from $100 \mathrm{ng}$ RNA per 96-well plate prepared by RNeasy kit (Qiagen, \#74104) and converted with the RT ${ }^{2}$ First Strand kit (Qiagen \# 330401).

Extracellular flux analysis. Extracellular flux analyses were carried out with a Seahorse XF-96 analyzer as previously published. ${ }^{59}$ Cells were isolated and cultured as indicated and washed three times in seahorse assay medium. Cells were analyzed for cell count and viability and seeded at $8.9 \times 10^{4}-2.5 \times 10^{5}$ cells per well (same number of viable cells used for compared data sets). Mitochondrial metabolism (OCRs) and glycolysis (ECAR) were analyzed with Seahorse Mito and Glycolysis Stress Test kits (Agilent, Waldbronn, Germany) according to the manufacturer's instructions.

CRISPR-Cas9 mediated knockout of EFhd1 in 38B9 pro B cells. The guide RNA targeting the EFhd1 gene was designed to bind within the first exon using the Zhang Lab online tool (http://crispr.mit.edu) (sgRNA EFhd1 (1): 5'-CAACGACATCCACCAGGGTACAGCG-3', sgRNA EFhd1 (2): 5'-AAACCG CTGTACCCTGGTGGATGTC-3'). Oligos of $10 \mu \mathrm{M}$ were incubated in $10 \mu \mathrm{l} \mathrm{H}_{2} \mathrm{O}$ at $95^{\circ} \mathrm{C}$ for 5 min and ligated into the BbSI digested px458 vector (pSpCas9(BB)-2AGFP) ${ }^{60}$ with T4 DNA ligase (New England Biolabs, Frankfurt, Germany) according to the manufacturer's instructions. The pro B-cell line $38 \mathrm{Bg}^{25}$ was transfected with the px458 vector containing the guide RNA using the Amaxa Cell Line Nucleofector Kit L (Lonza, Köln, Germany) according to the manufacturer's instructions. Twentyfour hours after transfection GFP-positive cells were sorted individually into 96-well plates and cultivated until further analysis. Out of 53 clones grown originally, 11 survived, 2 had a shortened protein, 4 contained a full-length EFhd1 protein with normal abundance and served as controls, and no EFhd1 protein was detectable anymore in 5 clones.

Data and statistical analysis. GraphPad Prism 5 (GraphPad Software, LaJolla, CA, USA) was used for all statistical analyses. Mann-Whitney- $U$ tests and unpaired Student's $t$-tests were used for statistical comparison and calculation of statistical significance depending on whether data passed Kolmogorov-Smirnov normal distribution tests. For comparison of more than four groups, ANOVA with Bonferroni correction was used. Significance is shown as ${ }^{*} P \leq 0.05,{ }^{* \star} P \leq 0.01$ and ${ }^{\star \star \star} P \leq 0.001$

\section{Conflict of Interest}

The authors declare no conflict of interest.

Acknowledgements. We thank Dr. Carlo Croce for the $\mathrm{V}_{\mathrm{H}} \mathrm{P}-\mathrm{E} \mu \mathrm{H}$ vector used to generate the transgene cassette, Dr. Roberta Pelanda for pIVHL2neo, Dr. Irmgard Förster for Rag $1^{-1}$ mice, Dr. Chris Paige for R5B cells and Dr. Jan Tuckermann for support. We also thank Drs. Mark Shlomcik and Florian Weisel for helpful comments during preparation of this manuscript. We thank Uwe Appelt and Markus Mroz for cell sorting and Stefan Hofmann as well as Domenica Saul for technical assistance. This work was supported by grants from the Deutsche Forschungsgemeinschaft (DFG) (TRR130, to DM, H-MJ, THW; SPP1468, to DM and AB, IRTG1660, to DM, H-MJ, THW).

\section{Author contributions}

MS, SD and DM designed experiments, performed experiments, analyzed data and wrote the paper. DM designed experiments and wrote the paper. MB and THW designed and performed the experiments. KF, DR, SU and TS performed experiments. $\mathrm{AB}$, WS and $\mathrm{H}-\mathrm{MJ}$ provided important conceptual input and wrote the paper.
1. Melchers $F$. The pre-B-cell receptor: selector of fitting immunoglobulin heavy chains for the B-cell repertoire. Nat Rev Immunol 2005; 5: 578-584.

2. Vettermann $C$, Jäck HM. The pre-B cell receptor: turning autoreactivity into self-defense. Trends Immunol 2010; 31: 176-183.

3. Young F, Ardman B, Shinkai Y, Lansford R, Blackwell TK, Mendelsohn M et al. Influence of immunoglobulin heavy- and light-chain expression on B-cell differentiation. Genes Dev 1994; 8: 1043-1057.

4. Mombaerts P, Johnson RS, Herrup K, Tonegawa S, Papaioannouo VE. RAG-1-deficient mice have no mature B and T lymphocytes. Cell 1992; 68: 869-877.

5. Guo B, Kato RM, Garcia-Lloret M, Wahl MI, Rawlings DJ. Engagement of the human pre-B cell receptor generates a lipid raft-dependent calcium signaling complex. Immunity 2000; 13: 243-253.

6. Hess J, Werner A, Wirth T, Melchers F, Jäck HM, Winkler TH. Induction of pre-B cell proliferation after de novo synthesis of the pre-B cell receptor. Proc Natl Acad Sci USA 2001; 98: $1745-1750$.

7. Milne CD, Paige CJ. IL-7: a key regulator of B lymphopoiesis. Semin Immunol 2006; 18 : 20-30.

8. Clark MR, Mandal M, Ochiai K, Singh H. Orchestrating B cell lymphopoiesis. Nat Rev Immunol 2013; 14: 69-80.

9. Hardy RR, Carmack CE, Shinton SA, Kemp JD, Hayakawa K. Resolution and characterization of pro-B and pre-pro-B cell stages in normal mouse bone marrow. $J$ Exp Med 1991; 173: 1213-1225.

10. Kikuchi K, Kasai H, Watanabe A, Lai AY, Kondo M. IL-7 specifies B cell fate at the common lymphoid progenitor to pre-ProB transition stage by maintaining early $B$ cell factor expression. J Immunol 2008; 181: 383-392.

11. Wofford JA, Wieman HL, Jacobs SR, Zhao Y, Rathmell JC, Jeffrey C. IL-7 promotes Glut1 trafficking and glucose uptake via STAT5-mediated activation of Akt to support T cell survival IL-7 promotes Glut1 trafficking and glucose uptake via STAT5-mediated activation of Akt to support T cell survival. Blood 2007; 111: 2101-2112.

12. Baracho GV, Miletic AV, Omori SA, Cato MH, Rickert RC. Emergence of the PI3-kinase pathway as a central modulator of normal and aberrant B cell differentiation. Curr Opin Immunol 2011; 23: 178-183.

13. Ochiai K, Maienschein-Cline M, Mandal M, Triggs JR, Bertolino E, Sciammas R et al. A selfreinforcing regulatory network triggered by limiting $\mathrm{IL}-7$ activates pre-BCR signaling and differentiation. Nat Immunol 2012; 13: 300-307.

14. Fleming HE, Paige CJ. Cooperation between IL-7 and the pre-B cell receptor: a key to B cell selection. Semin Immunol 2002; 14: 423-430.

15. Flemming $A$, Brummer $T$, Reth $M$, Jumaa $H$. The adaptor protein SLP-65 acts as a tumor suppressor that limits pre-B cell expansion. Nat Immunol 2003; 4: 38-43.

16. Caro-Maldonado A, Wang R, Nichols AG, Kuraoka M, Milasta S, Sun LD et al. Metabolic reprogramming is required for antibody production that is suppressed in anergic but exaggerated in chronically BAFF-exposed B cells. J Immunol 2014; 192: 3626-3636.

17. Agathocleous M, Harris WA. Metabolism in physiological cell proliferation and differentiation. Trends Cell Biol 2013; 23: 484-492.

18. Yasuda $T$, Sanjo $H$, Pagès G, Kawano $Y$, Karasuyama $H$, Pouysségur J et al. Erk kinases link pre-B cell receptor signaling to transcriptional events required for early $\mathrm{B}$ cell expansion. Immunity 2008; 28: 499-508.

19. Schuh W, Meister S, Herrmann K, Bradl H, Jäck HM. Transcriptome analysis in primary B lymphoid precursors following induction of the pre-B cell receptor. Mol Immunol 2008; 45: 362-375.

20. Park H, Staehling K, Tsang M, Appleby MW, Brunkow ME, Margineantu D et al. Disruption of Fnip1 reveals a metabolic checkpoint controlling B lymphocyte development. Immunity 2012; 36: 769-781.

21. Dütting S, Brachs S, Mielenz D. Fraternal twins: Swiprosin-1/EFhd2 and Swiprosin-2/EFhd1, two homologous EF-hand containing calcium binding adaptor proteins with distinct functions. Cell Commun Signal 2011; 9: 2

22. Hajnoczky G, Booth D, Csordás G, Debattisti V, Golenár T, Naghdi S et al. Reliance of ER mitochondrial calcium signaling on mitochondrial EF-hand Ca2+ binding proteins: Miros, MICUs, LETM1 and solute carriers. Curr Opin Cell Biol 2014; 29: 133-141.

23. Mootha VK, Bunkenborg J, Olsen JV, Hjerrild M, Wisniewski JR, Stahl E et al. Integrated analysis of protein composition, tissue diversity, and gene regulation in mouse mitochondria. Cell 2003; 115: 629-640.

24. Tominaga M, Kurihara H, Honda S, Amakawa G, Sakai T, Tomooka Y. Molecular characterization of mitocalcin, a novel mitochondrial $\mathrm{Ca} 2+$-binding protein with $\mathrm{EF}$-hand and coiled-coil domains. J Neurochem 2006; 96: 292-304

25. Alt F, Rosenberg N, Lewis $S$, Thomas E, Baltimore D. Organization and reorganization of immunoglobulin genes in A-MULV- transformed cells: rearrangement of heavy but not light chain genes. Cell 1981; 27: 381-390.

26. Brachs S, Lang C, Buslei R, Purohit P, Fürnrohr B, Kalbacher $\mathrm{H}$ et al. Monoclonal antibodies to discriminate the EF hand containing calcium binding adaptor proteins EFhd1 and EFhd2. Monoclon Antib Immunodiagn Immunother 2013; 32: 237-245.

27. Bossen C, Murre CS, Chang AN, Mansson R, Rodewald H-R, Murre C. The chromatin remodeler Brg1 activates enhancer repertoires to establish B cell identity and modulate cell growth. Nat Immunol 2015; 16: 775-784.

28. Chow KT, Timblin GA, McWhirter SM, Schlissel MS. MK5 activates Rag transcription via Foxo1 in developing B cells. J Exp Med 2013; 210: 1621-1634. 
29. Vazquez F, Lim J-H, Chim H, Bhalla K, Girnun G, Pierce K et al. P. PGC1 $\alpha$ expression defines a subset of human melanoma tumors with increased mitochondrial capacity and resistance to oxidative stress. Cancer Cell 2013; 23: 287-301.

30. Henzi T, Schwaller B. Antagonistic regulation of parvalbumin expression and mitochondrial calcium handling capacity in renal epithelial cells. PLOS ONE 2015; 10: e0142005.

31. Hou T, Jian C, Xu J, Huang AY, Xi J, Hu K et al. Identification of EFHD1 as a novel Ca2+ sensor for mitoflash activation. Cell Calcium 2016; 59: 262-270.

32. Hou T, Wang $X, M a Q$, Cheng H. Mitochondrial flashes: new insights into mitochondrial ROS signalling and beyond. J Physiol 2014; 17; 3703-3713.

33. Tzur A, Moore JK, Jorgensen P, Shapiro HM, Kirschner MW. Optimizing optical flow cytometry for cell volume-based sorting and analysis. PLOS ONE 2011; 6: e16053.

34. Avramidou A, Kroczek C, Lang C, Schuh W, Jäck H-M, Mielenz D. The novel adaptor protein Swiprosin-1 enhances BCR signals and contributes to BCR-induced apoptosis. Cell Death Differ 2007; 14: 1936-1947.

35. Milne CD, Corfe SA, Paige CJ. Heparan sulfate and heparin enhance ERK phosphorylation and mediate preBCR-dependent events during B lymphopoiesis. J Immunol 2008; 180 : 2839-2847.

36. Martin F, Won WJ, Kearney JF. Generation of the germline peripheral B cell repertoire: VH81X-lambda B cells are unable to complete all developmental programs. J Immunol 1998; 160: 3748-3758.

37. Koslowski M, Sahin U, Dhaene K, Huber C, Türeci Ö. MS4A12 is a colon-selective store-operated calcium channel promoting malignant cell processes. Cancer Res 2008; 68: 3458-3466.

38. Möröy T, Fisher P, Guidos C, Ma A, Zimmerman K, Tesfaye A et al. IgH enhancer deregulated expression of L-myc: abnormal $T$ lymphocyte development and $\mathrm{T}$ cell lymphomagenesis. EMBO J 1990; 9: 3659-3666.

39. Clark MR, Mandal M, Ochiai K, Singh H. Orchestrating B cell lymphopoiesis through interplay of IL-7 receptor and pre-B cell receptor signalling. Nat Rev Immunol 2014; 14: 69-80.

40. Hedrick SM. The cunning little vixen: Foxo and the cycle of life and death. Nat Immunol 2009; 10: 1057-1063.

41. Treiber T, Mandel EM, Pott S, Györy I, Firner S, Liu ET et al. Early B cell factor 1 regulates B cell gene networks by activation, repression, and transcription- independent poising of chromatin. Immunity 2010; 32: 714-725.

42. Hurt EM, Thomas SB, Peng B, Farrar WL. Molecular consequences of SOD2 expression in epigenetically silenced pancreatic carcinoma cell lines. Br J Cancer 2007; 97: 1116-1123.

43. Barthel A, Okino ST, Liao J, Nakatani K, Li J, Whitlock JP et al. Regulation of GLUT1 gene transcription by the serine/threonine kinase Akt1. J Biol Chem 1999; 274: 20281-20286.

44. Rakhshandehroo M, Knoch B, Müller M, Kersten S. Peroxisome proliferator-activated receptor alpha target genes. PPAR Res 2010; 2010: 612089.

45. Zhang S, Yang C, Yang Z, Zhang D, Ma X, Mills G et al. Homeostasis of redox status derived from glucose metabolic pathway could be the key to understanding the Warburg effect. Am J Cancer Res 2015; 5: 1265-1280.
46. Herzog S, Reth M, Jumaa H. Regulation of B-cell proliferation and differentiation by pre-Bcell receptor signalling. Nat Rev Immunol 2009; 9: 195-205.

47. Amin $\mathrm{RH}$, Schlissel MS. Foxo1 directly regulates the trancription of recombination activating genes during B cell development. Nat Immunol 2008; 9: 613-622.

48. Hofmann AD, Beyer M, Krause-Buchholz U, Wobus M, Bornhäuser M, Rödel G. Oxphos supercomplexes as a hallmark of the mitochondrial phenotype of adipogenic differentiated human MSCS. PLOS ONE 2012; 7: e35160.

49. Villena JA. New insights into PGC-1 coactivators: redefining their role in the regulation of mitochondrial function and beyond. FEBS J 2015; 282: 647-672.

50. Zhou Z, Zhou J, Du Y. Estrogen receptor alpha interacts with mitochondrial protein HADHB and affects beta-oxidation activity. Mol Cell Proteomics 2012; 11: M111.011056.

51. Shojaee S, Chan LN, Buchner M, Cazzaniga V, Cosgun KN, Geng H et al. PTEN opposes negative selection and enables oncogenic transformation of pre-B cells. Nat Med 2016; 4 : 379-387.

52. Mielenz D, Ruschel A, Vettermann C, Jäck H-M. Immunoglobulin mu heavy chains do not mediate tyrosine phosphorylation of Ig alpha from the ER-cis-Golgi. J Immunol 2003; 171: 3091-3101.

53. Bichi R, Shinton SA, Martin ES, Koval A, Calin GA, Cesari R et al. Human chronic lymphocytic leukemia modeled in mouse by targeted TCL1 expression. Proc Natl Acad Sci USA 2002; 99: 6955-6960.

54. Wellmann U, Letz M, Herrmann M, Angermüller S, Kalden JR, Winkler TH. The evolution of human anti-double-stranded DNA autoantibodies. Proc Natl Acad Sci USA 2005; 102 : 9258-9263.

55. Pelanda R, Schaal S, Torres RM, Rajewsky K. A prematurely expressed $\lg ($ kappa) transgene, but not a $\mathrm{V}($ kappa $) \mathrm{J}($ kappa) gene segment targeted into the Ig(kappa) locus, can rescue B cell development in lambda5-deficient mice. Immunity 1996; 5: 229-239.

56. Martin DA, Bradl H, Collins TJ, Roth E, Jäck H-M, Wu GE. Selection of Ig mu heavy chains by complementarity-determining region 3 length and amino acid composition. J Immunol 2003; 171: 4663-4671.

57. Milne CD, Fleming HE, Paige CJ. IL-7 does not prevent pro-B/pre-B cell maturation to the immature/slgM(+) stage. Eur J Immunol 2004; 34: 2647-2655.

58. Spandidos A, Wang X, Wang H, Seed B. PrimerBank: a resource of human and mouse PCR primer pairs for gene expression detection and quantification. Nucleic Acids Res 2010; 38: D792-799.

59. Jitschin R, Hofmann AD, Bruns H, GießI A, Bricks J, Berger J et al. Mitochondrial metabolism contributes to oxidative stress and reveals therapeutic targets in chronic lymphocytic leukemia. Blood 2014; 123: 2663-2672.

60. Ran FA, Hsu PD, Wright J, Agarwala V, Scott DA, Zhang F. Genome engineering using the CRISPR-Cas9 system. Nat Prot 2013; 8: 2281-2308.

\section{Supplementary Information accompanies this paper on Cell Death and Differentiation website (http://www.nature.com/cdd)}

